\title{
The surface energy balance of a polygonal tundra site in northern Siberia - Part 1: Spring to fall
}

\author{
M. Langer, S. Westermann, S. Muster, K. Piel, and J. Boike \\ Alfred-Wegener-Institute for Polar and Marine Research, Telegrafenberg A43, 14473 Potsdam, Germany \\ Received: 17 June 2010 - Published in The Cryosphere Discuss.: 12 July 2010 \\ Revised: 26 January 2011 - Accepted: 11 February 2011 - Published: 8 March 2011
}

\begin{abstract}
In this article, we present a study on the surface energy balance of a polygonal tundra landscape in northeast Siberia. The study was performed during half-year periods from April to September in each of 2007 and 2008. The surface energy balance is obtained from independent measurements of the net radiation, the turbulent heat fluxes, and the ground heat flux at several sites. Short-wave radiation is the dominant factor controlling the magnitude of all the other components of the surface energy balance during the entire observation period. About $50 \%$ of the available net radiation is consumed by the latent heat flux, while the sensible and the ground heat flux are each around 20 to $30 \%$. The ground heat flux is mainly consumed by active layer thawing. About $60 \%$ of the energy storage in the ground is attributed to the phase change of soil water. The remainder is used for soil warming down to a depth of $15 \mathrm{~m}$. In particular, the controlling factors for the surface energy partitioning are snow cover, cloud cover, and the temperature gradient in the soil. The thin snow cover melts within a few days, during which the equivalent of about $20 \%$ of the snow-water evaporates or sublimates. Surface temperature differences of the heterogeneous landscape indicate spatial variabilities of sensible and latent heat fluxes, which are verified by measurements. However, spatial differences in the partitioning between sensible and latent heat flux are only measured during conditions of high radiative forcing, which only occur occasionally.
\end{abstract}

\section{Introduction}

The thermal state of permafrost and its susceptibility towards degradation are largely determined by the surface energy balance. Many studies have revealed climate changes tak-

Correspondence to: $\mathrm{M}$. Langer

(moritz.langer@awi.de) ing place in the Arctic that are expected to continue (Overpeck et al., 1997; Hansen et al., 2001; Comiso, 2006; Overland et al., 2008). There is observational evidence that the turnover of energy and water have already been affected in the Arctic, involving the thermal state of permafrost (Serreze et al., 2000; Hinzman et al., 2005). Permafrost, which occupies about $25 \%$ of the land area of the Northern Hemisphere (Brown et al., 1997), is considered an important factor in the complex feedback mechanisms of the climate system, due to its massive carbon storage capabilities (Christensen and Cox, 1995; Callaghan et al., 2004; McGuire et al., 2006). Zimov et al. (2006) estimated that about $970 \mathrm{Gt}$ of carbon are stored in permafrost soils worldwide, which is about the same amount as the actual atmospheric carbon concentration. Until now it is unclear whether permafrost regions will turn into massive sources of greenhouse gases, such as methane and carbon dioxide, as the frozen soils begin to thaw (Hobbie et al., 2000; Davidson and Janssens, 2006). Recent measurements taken at wet tundra landscapes demonstrate the importance of the freeze and thaw dynamics for methane emission, which are related in a non-linear manner (Christensen et al., 2003; Sachs et al., 2008; Mastepanov et al., 2008). For this purpose, efforts have been initiated to incorporate permafrost and the annual freeze and thaw dynamics into global climate models (e.g., Stendel and Christensen, 2002; Lawrence and Slater, 2005; Nicolsky et al., 2007; Lawrence et al., 2008). In order to support and validate modeling, it is desirable to obtain regional process studies, which deliver important information about the landscape-specific energy balance characteristics and their determining factors. Many publications have demonstrated the value of such regional studies, which show that measurements on energy and water balance are still needed to improve the parameterizations of climate models (van den Hurk et al., 2000; Betts et al., 2001, 2003). Several energy balance studies are already available for the North American Arctic (e.g., Ohmura, 1982, 1984), and more are contained

Published by Copernicus Publications on behalf of the European Geosciences Union. 
in the comprehensive reviews by Eugster et al. (2000) and Lynch et al. (1999). For the European Arctic, including Svalbard, energy-balance studies are published by Lloyd et al. (2001) and Westermann et al. (2009). However, Siberian sites are not included and generally few published studies are available for the Siberian tundra (Kodama et al., 2007; Boike et al., 2008).

In this study we present data on the surface energy balance of a typical tundra landscape in northern Siberia collected between April and September during each of 2007 and 2008. A similar study about the winter aspects of the surfaces energy balance is given in a companion paper (Langer et al., 2010b) The study aims to (i) compile the surface energy balance at a polygonal tundra site during the summer half year period, (ii) determine the seasonal and spatial variability of each energy-balance component which gives insight in the driving processes of the coupled permafrost-snow-atmosphere system, and (iii) identify the dominant factors that determine the energy partitioning and subsurface heat budget (active layer dynamics, permafrost temperatures).

\section{Study site}

The study site is located on Samoylov Island $\left(72^{\circ} 22^{\prime} \mathrm{N}\right.$; $126^{\circ} 30^{\prime} \mathrm{E}$ ) at the upper part of the Lena River Delta (Fig. 1). It is characterized by a wet tundra landscape typical of northern Siberia. Samoylov Island covers an area of about $4.5 \mathrm{~km}^{2}$, with an elevated eastern terrace and a lower western flood plain. The region features a typical arctic-continental climate, with a mean annual air temperature (MAAT) of about $-13^{\circ} \mathrm{C}$ and a total annual precipitation around $250 \mathrm{~mm}$ (Boike et al., 2008). The ice break-up of the Lena River and the snow melt usually start at the beginning of June. The snow-free period lasts until the end of September, and maximum air temperatures exceeding $20^{\circ} \mathrm{C}$ are typically reached during July. The regional climate and the synoptic conditions are influenced by both the Siberian High and the Polar Low pressure system. During the summer period, intermediate cyclone activity with low intensity is typically observed, while cyclones with high intensity but short lifetime are more frequently found in winter (Zhang et al., 2004). During the winter months, extremely cold air temperatures are reached which frequently fall below $-45^{\circ} \mathrm{C}$. The study site is in the zone of continuous permafrost, with permafrost depths reaching 500 to $600 \mathrm{~m}$ in the wider area around the study site (Grigoriev, 1960). The measurement site is located on the elevated terrace of the island, which is mainly characterized by low centered polygons. The polygonal structures are typically 50 to $100 \mathrm{~m}^{2}$ large. The study site is further characterized by many ponds, which mostly range over 0.5 to $1 \mathrm{~m}$ in depth. During the entire study period, the water table is close to the surface, so that the soils at the depressed polygonal centers are usually water-saturated while the elevated rims are comparatively dry. During the snow melt, when water drainage is impeded by the frozen soils, the lowered centers are temporally flooded. The vegetation at the wet centers is dominated by hydrophilic sedges and mosses, while the elevated dry rims are dominated by mesophytic dwarf shrubs, forbs, and mosses. More detailed descriptions of the vegetation and landscape characteristics are available; cf. Are and Reimnitz (2000), Kutzbach et al. (2004, 2007), Boike et al. (2008) and Sachs et al. (2008).

\section{Methods}

The energy-balance equation is written as

$Q_{\text {net }}=Q_{\mathrm{H}}+Q_{\mathrm{E}}+Q_{\mathrm{G}}+\left[Q_{\mathrm{melt}}\right]+C$,

where $Q_{\text {net }}$ denotes the net radiation, $Q_{\mathrm{H}}$ the atmospheric sensible heat flux, $Q_{\mathrm{E}}$ the atmospheric latent heat flux, $Q_{\mathrm{G}}$ the ground heat flux, and $Q_{\text {melt }}$ is the energy flux consumed by the snow melt. $Q_{\text {melt }}$ can be inferred from to the energy required to thaw the snow pack, $E_{\text {melt }}$, and the duration of the melt period. As independent field measurements of the components are subject to errors, a residual of the energy balance or closure term $C$ can remain. The energy fluxes are given in $\mathrm{Wm}^{-2}$ in the following. The measurement setup and the expected margins of error are described in detail in the following paragraphs.

\subsection{The radiation balance}

The net radiation is the most important term in the surface energy balance and can be written as

$Q_{\text {net }}=Q_{\mathrm{S} \downarrow}-Q_{\mathrm{S} \uparrow}+Q_{\mathrm{L} \downarrow}-Q_{\mathrm{L} \uparrow}$,

where $Q_{\mathrm{S} \downarrow}$ and $Q_{\mathrm{S} \uparrow}$ are the incoming and outgoing shortwave components, and $Q_{\mathrm{L} \downarrow}$ and $Q_{\mathrm{L} \uparrow}$ are the incoming and outgoing long-wave components, respectively. Using StefanBoltzmann law and Kirchhoff's law of thermal radiation the upwelling thermal radiation can also be written as.

$Q_{\mathrm{L} \uparrow}=(1-\epsilon) Q_{\mathrm{L} \downarrow}+\epsilon \sigma T_{\text {surf }}^{4}$,

where $\epsilon$ is the surface emissivity, $T_{\text {surf }}$ the surface temperature, and $\sigma$ is the Stefan-Boltzmann constant. Using Eq. (3) and the surface albedo $\alpha$ Eq. (2) can be rewritten as

$Q_{\text {net }}=Q_{\mathrm{S} \downarrow}(1-\alpha)+\epsilon Q_{\mathrm{L} \downarrow}-\epsilon \sigma T_{\text {surf }}^{4}$.

The present study uses a variety of sensors to determine the radiation components. The net radiation $Q_{\text {net }}$ is measured with the NR-Lite (Kipp \& Zonen, Netherlands) net-radiation sensors mounted in $1.5 \mathrm{~m}$ height. Additional net-radiation measurements (CNR1, Kipp \& Zonen, Netherlands) with higher accuracy are available during midsummer 2007 and for the entire observation period of 2008 (Fig. 2). The four-component CNR1 sensor measures all radiation-balance components separately. The sensor is located in the vicinity 

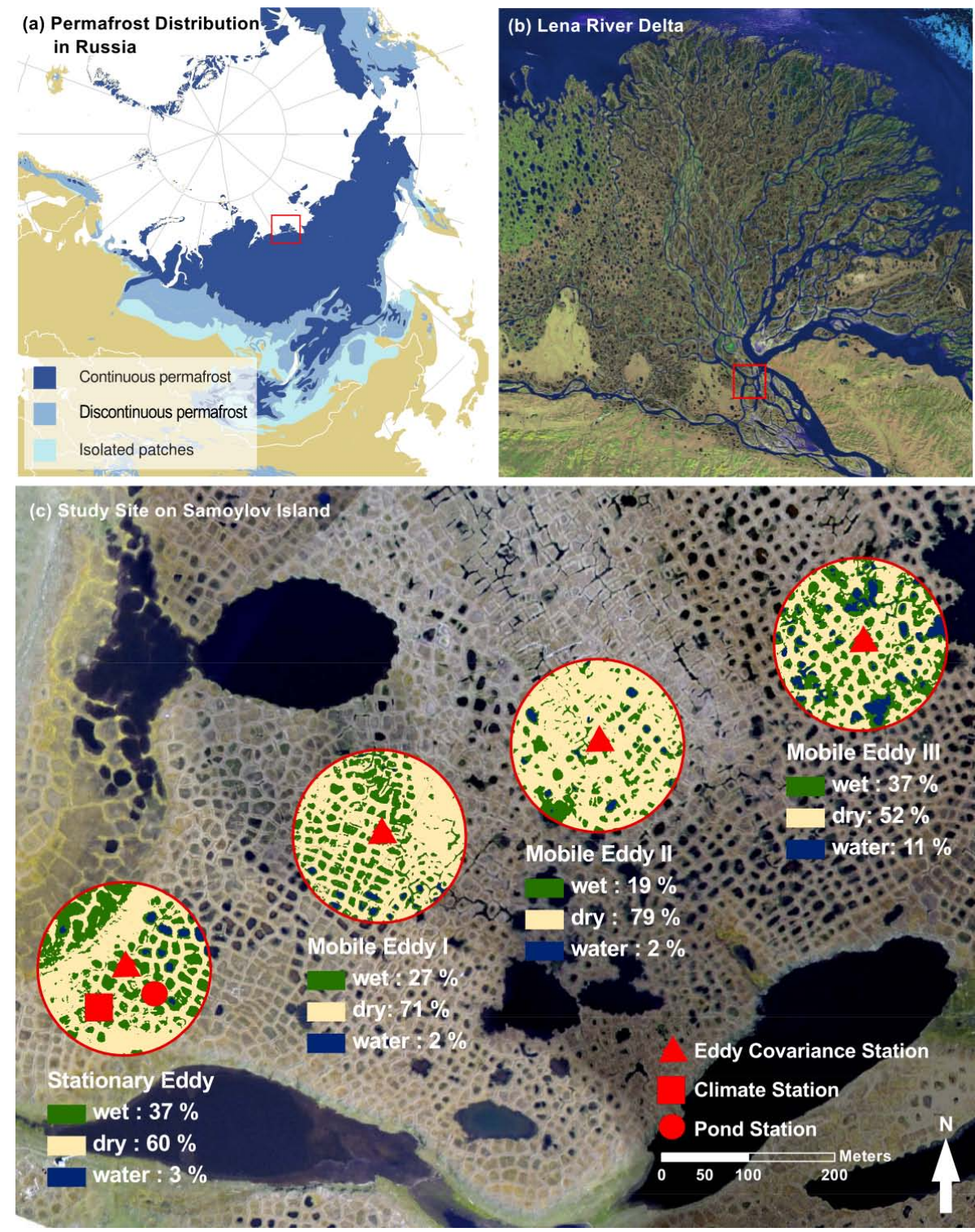

Fig. 1. (a) Permafrost distribution in Siberia (Brown et al., 1997); the location of the Lena River Delta is marked in red. (b) Satellite image of the Lena River Delta obtained from the Landsat Thematic Mapper (USGS, 2000); the location of Samoylov Island is marked in red. (c) High-resolution aerial image of the study site on Samoylov Island, where the considerable small-scale heterogeneity of the surface cover is visible. The locations of all installations are marked. The footprint areas of the eddy covariance systems are illustrated as circles with a radius similar to the average footprint extent. The fractions of wet, dry, and water surfaces in the relevant footprint areas are calculated using a footprint model of Schmid (1994) (see Sect. 3.2).

of the eddy covariance station and is mounted on a $2 \mathrm{~m}$ mast (Fig. 1). Further net radiation measurements with an NRLite sensor are conducted at a thermokarst pond, which is approximately $0.8 \mathrm{~m}$ deep. These additional measurements are performed to investigate differences in the radiation balance between the tundra surface and shallow water bodies, which are a frequent landscape element (Fig. 1). The evaluation of the accuracy of the employed net radiation sensors is difficult, since World Meteorological Organization (WMO) quality standards are not available for net-radiation sensors. Studies comparing the employed sensors with highaccuracy single component sensors (Brotzge and Duchon, 2000; Kohsiek et al., 2007) suggest a relative measurement accuracy of about $20 \%$ for the NR-Lite and about $10 \%$ for the CNR1 sensor. A sensor comparison for 1 week under field conditions shows that daily averages of the NR-Lite sensor are about 5 to $10 \mathrm{~W} \mathrm{~m}^{-2}$ lower compared to the values obtained by the four-component sensor. In most cases, this systematic offset is within the relative accuracy of the NR-Lite sensor, assuming the four-component CNR1 sensor gives the 

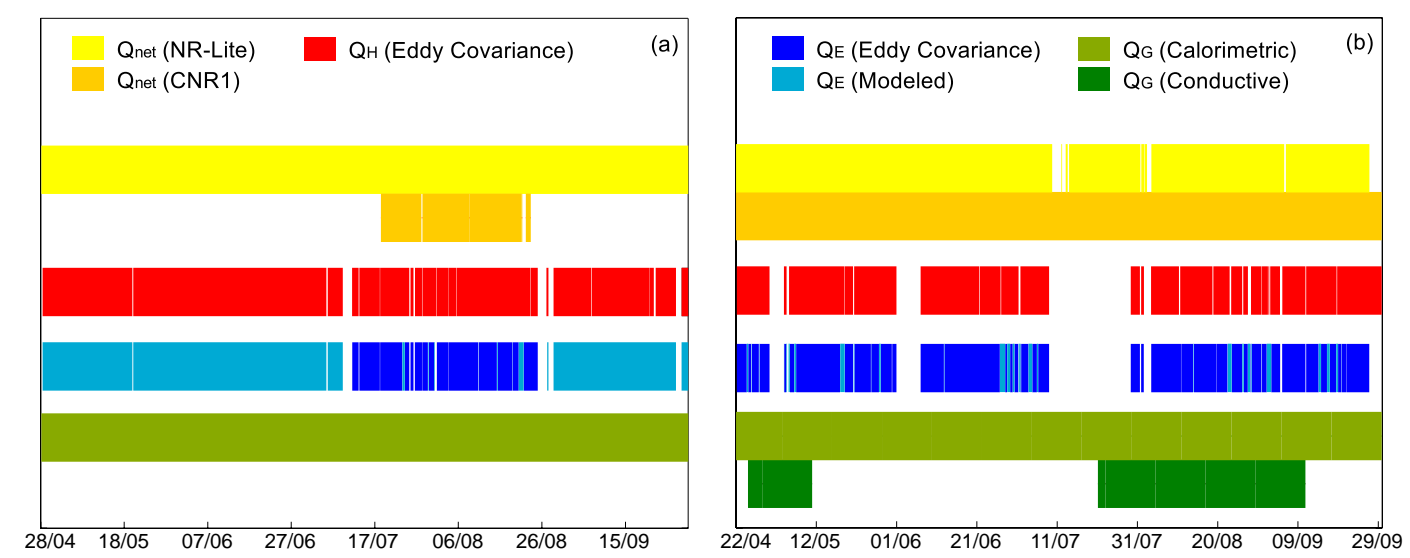

Fig. 2. Availability of net radiation $Q_{\text {net }}$, sensible heat flux $Q_{\mathrm{H}}$, latent heat flux $Q_{\mathrm{E}}$, and ground heat flux $Q_{\mathrm{G}}$ during the observation periods in (a) 2007 and (b) 2008. Values obtained by different sensors and approaches are indicated separately.

more accurate reading. However, we emphasize that the offset is beyond the assumed accuracy under conditions of low net radiation.

In addition to the net radiation sensors, measurements of the upwelling thermal radiation (CG1, Kipp \& Zonen, Netherlands) are available at the standard climate tower (Fig. 1), while spatial differences are measured with distributed infrared surface temperature sensors (IRTS$\mathrm{P}$, Apogee Instruments, USA). The infrared sensors are mounted on small tripods about $0.8 \mathrm{~m}$ above the surface and are directed at different tundra soils. According to instrument specifications, the IRTS-P sensors measure over a spectral range of $7-14 \mu \mathrm{m}$ and deliver brightness temperatures with accuracies of about $\pm 0.5^{\circ} \mathrm{C}$ (Bugbee et al., 1998). The true surface temperature $T_{\text {surf }}$ and upwelling thermal radiation $Q_{\mathrm{L} \uparrow}$ are calculated similar to the approach described by Langer et al. (2010a) which accounts for the surface emissivity $\epsilon$ and the back scattered fraction of down welling thermal radiation (Eq. 3). In accordance with Langer et al. (2010a) we assume emissivities of 0.98 for wet, and 0.96 for dry tundra surfaces. For averaging periods longer than a week the expected error on the true surface temperature is smaller than $\pm 1^{\circ} \mathrm{C}$ (Langer et al., 2010a). This relates to an error in $Q_{\mathrm{L} \uparrow}$ of about $\pm 5 \mathrm{~W} \mathrm{~m}^{-2}$ in the relevant temperature range from -10 to $30^{\circ} \mathrm{C}$.

To get a more differentiated picture of the short-wave radiation balance, spatially distributed measurements of the outgoing short-wave radiation are performed with a mobile short-wave radiation sensor (SP1110, Skye Instruments, USA). The measurements are performed under clear-sky conditions over a period of 3 to $4 \mathrm{~h}$ around solar noon. Based on these time series, average albedo values for wet and dry surfaces are inferred using incoming short-wave radiation, as measured by the CNR1 sensor. Following the accuracies of the sensors given in the manuals, the uncertainty for the calculated albedo value are on the order of $10 \%$.

\subsection{Turbulent heat fluxes}

The turbulent fluxes of momentum $u_{*}^{2}$, sensible heat $Q_{\mathrm{H}}$, and latent heat $Q_{\mathrm{E}}$, are determined with the eddy covariance method. The applied eddy covariance system consists of a Campbell C-SAT 3-D sonic anemometer and open path LICOR LI-7500 $\mathrm{CO}_{2}$ and $\mathrm{H}_{2} \mathrm{O}$ gas analyzer mounted on a $2.4 \mathrm{~m}$ mast. The measurement height is well above the blending height of the polygonal surface structures which typically range from 5 to $20 \mathrm{~m}$ in size (Garratt, 1994). Hence, the eddy covariance measurements can be considered a spatial average over the heterogeneous tundra surface in the fetch of the system. The data is sampled at a rate of $20 \mathrm{~Hz}$ using a Campbell CR3000 data logger. Sonic anemometer measurements are conducted during the entire observation period, while the gas analyzer is operated only during the field trips, where there is a reliable power supply and regular maintenance (Fig. 2).

The eddy covariance method is based on high-frequency measurements of the sonic temperature $T_{\mathrm{S}}$, the specific humidity $q$, and the horizontal and vertical wind-speed components, $u$ and $w$. The turbulent flux components can be evaluated from the covariances $\overline{u^{\prime} w^{\prime}}, \overline{T_{\mathrm{s}}^{\prime} w^{\prime}}$ and $\overline{q^{\prime} w^{\prime}}$ of the fluctuations $u^{\prime}, w^{\prime}, T_{\mathrm{s}}^{\prime}$ and $q^{\prime}$ around the average values of the above quantities as

$u_{*}^{2}=\overline{u^{\prime} w^{\prime}}$,

$Q_{\mathrm{HB}}=\rho_{\mathrm{air}} c_{p} \overline{T_{\mathrm{v}}^{\prime} w^{\prime}}$,

$Q_{\mathrm{H}}=\rho_{\mathrm{air}} c_{p} \overline{T_{\mathrm{a}}^{\prime} w^{\prime}}=\rho_{\mathrm{air}} c_{p}\left(\overline{T_{\mathrm{s}}^{\prime} w^{\prime}}-0.51 \overline{T_{\mathrm{a}}} \overline{q^{\prime} w^{\prime}}\right)$,

$Q_{\mathrm{E}}=\rho_{\mathrm{air}} L_{\mathrm{lg}} \overline{q^{\prime} w^{\prime}}$,

where $T_{\mathrm{a}}$ is the absolute air temperature, $Q_{\mathrm{HB}}$ is the buoyancy flux, $c_{p}$ is the specific heat capacity of air at constant pressure, and $L_{\mathrm{lg}}$ is the specific latent heat of vaporization of water (e.g. Foken, 2006). Note that, in the case of measurements over a frozen (snow) surface, $L_{\mathrm{lg}}$ must be 
replaced by the latent heat of sublimation $L_{\mathrm{sg}}$. The buoyancy flux $Q_{\mathrm{HB}}$ differs from the true sensible heat flux $Q_{\mathrm{H}}$ due to the difference between the virtual temperature $T_{\mathrm{v}}$ and the real air temperature $T_{\mathrm{a}}$. The virtual temperature is almost equal to the measured sonic temperature $T_{\mathrm{S}} \approx T_{\mathrm{V}}$, so that the buoyancy flux is directly measured by the sonic anemometer (Liu and Foken, 2001). To obtain the true sensible heat flux $Q_{\mathrm{H}}$, the buoyancy flux must be corrected according to Eq. (7), which requires measurements of the humidity flux $q^{\prime} w^{\prime}$ (Schotanus et al., 1983). As the LICOR gas analyzer is not operated continuously (see above), this correction cannot be applied during parts of the spring and summer period in 2007 (Fig. 2). The error induced by interpreting the buoyancy flux as sensible heat flux can be estimated using the Bowen ratio, $Q_{\mathrm{H}} / Q_{\mathrm{E}}$. For Bowen ratios of approximately 0.5 and average air temperatures of $\bar{T} \approx 300 \mathrm{~K}$, the offset is around $15 \%$, which constitutes an additional error during the respective periods. In addition, the eddy covariance system delivers a measure of the atmospheric stability $\zeta$ which can be calculated from fluxes of momentum and heat as described in Appendix D.

The turbulent fluxes are calculated for $30 \mathrm{~min}$ intervals with the "QA/QC" software package "TK2" (Mauder and Foken, 2004; Mauder et al., 2008), which includes standard corrections and quality tests. Besides the aforementioned correction of the buoyancy flux, processing the data involves an adjustment of the horizontal and vertical wind speed components using the planar fit correction (Wilczak et al., 2001), and an adjustment due to the displacement between anemometer and gas analyzer (Moore, 1986). The applied quality assessment follows the scheme of Foken et al. (2005) based on tests for stationarity of the turbulence characteristic. The stationarity criterion is considered to be sufficiently fulfilled (quality flags 1 and 2) if the average covariance inferred from $5 \mathrm{~min}$ sub-intervals do not deviate by more than $30 \%$ from the covariance value over the entire $30 \mathrm{~min}$ interval (Foken et al., 2005). A graduation of the deviation is used as a quality measure, expressed with quality flags between 1 and 9. In this study, we accept sensible heat fluxes when both the quality flags of $\overline{u^{\prime} w^{\prime}}$ and $\overline{T_{\mathrm{s}}^{\prime} w^{\prime}}$ are 6 or better. For the latent heat fluxes $Q_{\mathrm{E}}$, we use the quality flags of $\overline{u^{\prime} w^{\prime}}$ and $\overline{q^{\prime} w^{\prime}}$, respectively. This quality standard is recommended for long-term observations (Foken and Wichura, 1996). In other field experiments, this quality level is found to be associated with a relative measurement accuracy of about $15 \%$ (Mauder et al., 2006), which we assume as the general accuracy of the obtained turbulent heat fluxes. The quality assessment causes a data reduction of about $3 \%$ for the sensible and about $4 \%$ for the latent heat fluxes. A further data reduction of about $14 \%$ originates from the exclusion of the wind sector in the 263-277 band, which is considered to be the lee area of the mast, on which the anemometer is mounted. In order to obtain the magnitude of the latent heat fluxes, when measurements of the LICOR gas analyzer are not available, we use a model that is based on the parametrization of turbulent fluxes introduced by Høgstrøm (1988) which is described in detail in Appendix D. Periods which are filled with modeled values are indicated in Fig. 2. Parameters required for modeling, such as roughness lengths and surface resistance to evaporation, are determined by model optimization to available measurements. A detailed description of the used model is given in Appendix D. An overview of the available dataset is given in Table 2, where the modeled latent heat fluxes are also marked.

In addition, the spatial consistence of the turbulent heat fluxes at the study site is investigated by a second eddy covariance system during the summer of 2008. The second system is identical to the first one and is used as a mobile station, which is moved at a weekly interval along a $1 \mathrm{~km}$ east-west transect across the study site (Fig. 1), while the first system provides simultaneous measurements at the reference location. The flux source area of each half-hour value is determined with the footprint model of Schmid (1994). For the footprint calculations, we assume a constant roughness length $z_{0}=10^{-3} \mathrm{~m}$, which we directly infer from the turbulence measurements under neutral atmospheric stratification (Foken, 2006). This value is consistent with typical roughness lengths reported for short grassland (Oke, 1987; Foken, 2006). The fractions of wet and dry tundra areas, and those of polygonal ponds for eddy footprint areas, are derived from aerial photographs using supervised classification based on field mapping. The locations of the stationary and the mobile eddy system feature differences in average surface soil moisture according to differences in the polygonal structures.

\subsection{Ground heat flux}

In this study, we apply two different methods to determine the ground heat flux on different time scales.

\subsubsection{Calorimetric method}

The calorimetric method is used to evaluate the average ground heat flux over longer periods (Appendix B). The method looks at soil temperature and moisture measurements and calculates the average ground heat flux from changes in the sensible and latent heat content of a soil column. The method has been successfully applied in several permafrost regions and is described, e.g., by Boike et al. (1998) and Westermann et al. (2009). We use a measurement setup consisting of an active layer temperature and moisture profile to a depth of $0.5 \mathrm{~m}$, which features 5 thermistors (107-L, Campbell Scientific, USA) and 5 Time-Domain-Reflectometry (TDR) soil moisture probes (CS610-L, Campbell Scientific, USA). The calorimetric methods requires temperature measurements to the depth at which no temperature changes occur in the considered time interval (Appendix B). The temperature profile at the depth of zero annual amplitude $(15 \mathrm{~m})$ is measured in a $26 \mathrm{~m}$ bore-hole with a temperature chain featuring 24 thermistors (XR-420, RBR Ltd., Canada). 
Table 1. Used soil and snow parameters for ground-heat flux calculations. Values of porosity $P_{\mathrm{dry}}$ and water content $\theta_{\mathrm{w}}$ are inferred from soil sample analysis and measurements of in-situ soil water content. The heat capacities are calculated by weighting $C_{\mathrm{h}, \mathrm{w}}$ and $C_{\mathrm{h}, \mathrm{s}}$ according to water content and porosity. The thermal diffusivities $D_{\mathrm{h}}$ are determined using the conductive method (see Sect. 3.3.2), from which we obtain the thermal conductivities $K_{\mathrm{h}}$ in conjunction with the assumed heat capacity. The given uncertainties account for spatial variabilities of $C_{\mathrm{h}}, D_{\mathrm{h}}$, and $K_{\mathrm{h}}$ within the different soil classes.

\begin{tabular}{lccccc}
\hline Substrate & $P_{\text {dry }}$ & $\theta_{\mathrm{W}}$ & $C_{\mathrm{h}}\left[\mathrm{MJ} \mathrm{m}^{-3} \mathrm{~K}^{-1}\right]$ & $D_{\mathrm{h}}\left[\mathrm{m}^{2} \mathrm{~s}^{-1}\right] \times 10^{-6}$ & $K_{\mathrm{h}}\left[\mathrm{W} \mathrm{m}^{-1} \mathrm{~K}^{-1}\right]$ \\
\hline dry peat & $0.8 \pm 0.1$ & $0.1 \pm 0.1$ & $0.9 \pm 0.5$ & $0.16 \pm 0.01$ & $0.14 \pm 0.08$ \\
wet peat & $0.8 \pm 0.1$ & $0.7 \pm 0.1$ & $3.4 \pm 0.5$ & $0.19 \pm 0.04$ & $0.60 \pm 0.17$ \\
saturated peat & $0.8 \pm 0.1$ & $0.8 \pm 0.1$ & $3.8 \pm 0.2$ & $0.19 \pm 0.02$ & $0.72 \pm 0.08$ \\
snow & $\rho_{\text {snow }}=190 \pm 10 \mathrm{~kg} \mathrm{~m}^{-3}$ & $0.40 \pm 0.04$ & $0.54 \pm 0.04$ & $0.22 \pm 0.03$ \\
\hline
\end{tabular}

\subsubsection{Conductive method}

The conductive method is primarily used to evaluate the diurnal course of the ground heat flux though the uppermost surface of the ground (Westermann et al., 2009). The ground surface is defined to be either the soil or the snow surface, as appropriate. This method directly calculates the heat flux through the soil surface by solving the differential equation of conductive heat transport (Appendix C), which involves the determination of the thermal conductivity of the soil using shallow temperature profile measurements. As the conductive method is not feasible when a phase change of water occurs, we exclude the transition periods in spring and fall from such calculations. The chosen temperature profiles are installed between the surface and about $30 \mathrm{~cm}$ depth in different soil substrates, and consist of at least three thermocouples or thermistors with accuracies better than $0.2{ }^{\circ} \mathrm{C}$. The instrumented soil substrates are classified as dry, wet, or saturated peat soils (Table 1). The sensors for each profile are placed in soil layers that are judged to be homogeneous in composition following a visual examination. Furthermore, we assume constant thermal properties over the considered time intervals (Appendix C), which is a good assumption for wet and saturated soils.

During early spring, the heat flux through the snow cover can be calculated using a similar approach. The determination of the snow thermal properties is based on measurements of the snow density and temperature profiles that are conducted in spring 2008. The boundary conditions for the heat-flux calculations are obtained from an infrared surface temperature sensor and a thermistor located at the soil-snow interface. Snow heat fluxes are calculated for periods of constant snow depth, which is measured with an ultrasonic ranging sensor (SR50, Campbell Scientific, USA) located next to the measurement setup. The snow heat fluxes obtained must be considered a rough approximation, since the assumption of constant thermal snow properties may be violated in reality (e.g., Sturm et al., 1997; Zhang, 2005).

\subsubsection{Soil and snow parameters}

Both methods for calculating ground heat flux require knowledge about the thermal properties of soil or snow (cf. Appendices $\mathrm{B}, \mathrm{C}$ ). The heat capacity is inferred from soil component analyses of samples taken during the field campaigns and in-situ water content measurements. According to spatial variabilities in the soil properties, we assume an error of $10 \%$ on each soil fraction, such as water content, ice content, and solid soil matrix. A bulk heat capacity of $2.3 \pm 0.3 \mathrm{MJ} \mathrm{m}^{-3} \mathrm{~K}^{-1}$ is used for the solid soil fraction. The soil properties and the associated heat capacities obtained are depicted in Table 1. It is evident that large uncertainties in heat capacity occur at the dry peat soils, since even small variations in the soil composition induce errors of about $60 \%$. As a consequence, we do not evaluate soil heat fluxes at dry locations. The conductive method can determine further soil properties, such as thermal diffusivity and heat conductivity (Appendix C) as displayed in Table 1. For wet tundra soils, the diffusivity values obtained from different temperature profiles show variations in the range of $20 \%$, resulting in a combined error of about $30 \%$ for the heat conductivity. A similar error range is calculated for the snow heat conductivity, which we infer from the snow density and temperature profile measurements using the conductive method (see Appendix C). For simplicity, we assume an error of $30 \%$ as appropriate for all ground heat flux calculations, which accounts for the spatial variabilities of the soil properties. The uncertainty of the ground heat flux is about $10 \%$ larger than the errors assumed for the other energy balance components.

\subsection{Ancillary measurements}

Measurements of air temperature and relative humidity (MP100, Rotronic, Switzerland) are performed at the standard climate tower in the vicinity of the eddy covariance system (Fig. 1). In spring, the snow melt is evaluated, based on ultrasonic ranging sensors (SR50, Campbell Scientific, USA) located at the standard climate station and the polygonal pond. In addition, we approximate the evolution of snow-free areas during the ablation period. The snow-free area is roughly 


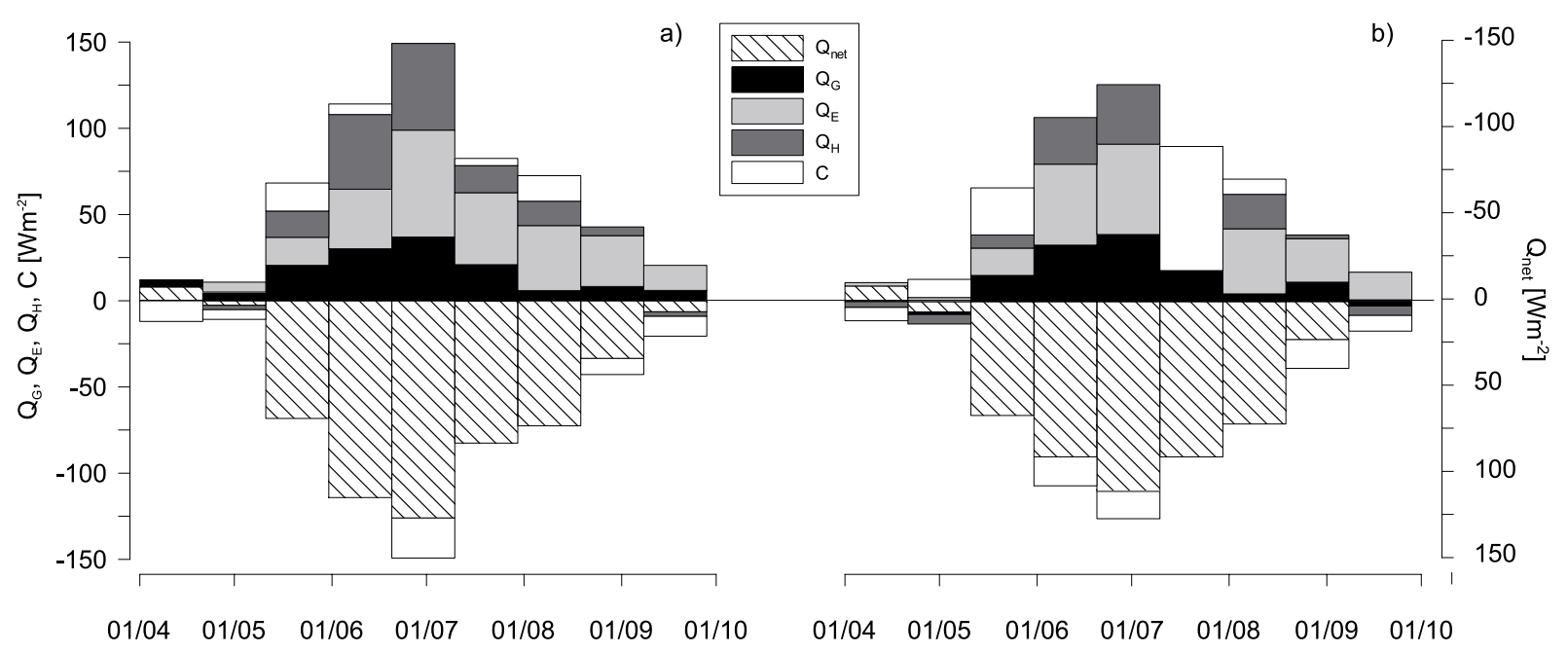

Fig. 3. The energy balance of (a) 2007 and (b) 2008. Heat fluxes are averaged over 20 days, and data gaps in the latent heat fluxes are filled by modeled values. For the visualization, the averaging intervals of 20 days are found to be a good compromise between temporal resolution and data density. The fraction of modeled latent heat fluxes is $68 \%$ in 2007 and $8 \%$ in 2008 . Averages are discarded if the data density is less than $60 \%$. Note that the net radiation is displayed on a second $y$-axis with respect to illustration.

estimated by means of visual inspection of daily photographs taken automatically from a $2 \mathrm{~m}$ mast at the measurement site. The latent heat content of the snow cover $E_{\text {melt }}$ is calculated from the average snow-water equivalent (SWE) at the study site. The SWE is inferred from spatially distributed measurements of snow density using a core-tube immediately before the onset of snow melt in 2008. The average snow density is evaluated by taking five cores at 20 different measurement locations. For the year 2007, for which snow-water equivalent measurements are not available, a similar density as in 2008 is assumed.

\section{Results}

\subsection{Seasonal energy balance characteristics}

The time span considered in this study consists of two intervals, each from April to September, in 2007 and 2008. The energy balances of both periods are depicted in Fig. 3 with averaging intervals of 20 days. For the description of the seasonal energy balance characteristics, we separate the observation period into three subsections according to seasonal climatic conditions. The spring section is characterized by the presence of the perennial snow cover and lasts until the end of snow melt. The summer section features air temperatures well above the freezing point, and the fall section is defined by the beginning of refreeze and occasional snow fall.

\subsubsection{Spring (1 April-31 May)}

During the spring period, the daily average air temperatures increase strongly from $-16^{\circ} \mathrm{C}$ to $6^{\circ} \mathrm{C}$ in 2007 and from $-25^{\circ} \mathrm{C}$ to $2^{\circ} \mathrm{C}$ in 2008 , with notable differences between both years. According to the ultrasonic snow depth sensor, the early spring snow depths are in the range from 0.30 and $0.35 \mathrm{~m}$ in both years. These point values are confirmed by spatially distributed snow-water equivalent measurements in 2008, which yield an average snow depth of about $0.30 \mathrm{~m}$, with an average snow density of $190 \mathrm{~kg} \mathrm{~m}^{-3}$. The onset and course of the snow melt are almost identical for both years. The snow melt starts in mid-May shortly after the beginning of the polar day and does not occur in a single event but is interrupted by declining air temperatures and subsequent snowfall. The first snow melt event lasts only a few days (1019 May 2007/10-14 May 2008), during which the elevated polygonal rims become partly snow-free (Fig. 4). The subsequent snow fall delivers only a few centimeters of additional snow cover, which disappear quickly in the second and final melt event (22-30 May 2007/21-29 May 2008). During and shortly after the snow melt, the polygonal centers are temporally flooded, when the frozen soils impedes water drainage. This period lasts from 10 to 14 days, and the standing water column features a depth of a few millimeters to centimeters.

In the following, we refer to the period before the onset of melting as the pre-melt period, while the subsequent time is denoted the snow melt period. The average net radiation is positive during the entire spring period and of similar magnitude in both years (Fig. 3). During the pre-melt period, the diurnal amplitude of the net radiation ranges from -40 to $50 \mathrm{~W} \mathrm{~m}^{-2}$, but increases rapidly during the melt period until the snow cover has completely disappeared. This rapid change in the net radiation is related to a gradual change of the surface albedo, which has a value 0.8 before and 0.2 after snow melt. The gradual change in the surface albedo is attributed to the successive melt out of the elevated polygonal rims. This change in the surface characteristics is reflected 
Table 2. Seasonal averages of the net radiation $Q_{\text {net }}$, the net short wave radiation $\Delta Q_{\mathrm{S}}$, the net long wave radiation $\Delta Q_{\mathrm{L}}$, the sensible heat flux $Q_{\mathrm{H}}$, the latent heat flux $Q_{\mathrm{E}}$, the ground heat flux $Q_{\mathrm{G}}$, the sensible fraction of the ground heat flux $Q_{\mathrm{G}}$, sensible, the latent fraction of the ground heat flux $Q_{\mathrm{G} \text {, latent }}$, the energy attributed to snow melt $E_{\text {melt }}$, and the closure term $C$. In addition, important ratios and climate parameters are given such as the surface temperature $T_{\text {surf }}$, the air temperature $T_{\text {air }}$, the relative humidity RH, and the total precipitation $P$. The springtime precipitation is replaced by the snow-water equivalent (SWE). The turbulent heat-flux values marked in bold are affected by minor data gaps, due to quality or lee-sector data exclusion.

\begin{tabular}{|c|c|c|c|c|c|c|}
\hline & \multicolumn{2}{|c|}{ Spring } & \multicolumn{2}{|c|}{ Summer } & \multicolumn{2}{|c|}{ Fall } \\
\hline & $\begin{array}{c}2007 \\
28 \text { Apr-31 May }\end{array}$ & $\begin{array}{c}2008 \\
22 \text { Apr-31 May }\end{array}$ & $\begin{array}{c}2007 \\
12 \text { Jul-23 Aug }\end{array}$ & $\begin{array}{c}2008 \\
7 \text { Jun-8 Jul } \\
\text { 29 Jul-30 Aug }\end{array}$ & $\begin{array}{c}2007 \\
1-30 \mathrm{Sep}\end{array}$ & $\begin{array}{c}2008 \\
1-30 \text { Sep }\end{array}$ \\
\hline$Q_{\text {net }}\left[\mathrm{W} \mathrm{m}^{-2}\right]$ & $44^{\mathrm{a}}$ & $27^{\mathrm{b}}$ & $81^{\mathrm{b}}$ & $104^{\mathrm{b}}$ & $7^{\mathrm{a}}$ & $11^{\mathrm{b}} 5^{\mathrm{a}}$ \\
\hline$\Delta Q_{\mathrm{S}}\left[\mathrm{W} \mathrm{m}^{-2}\right]$ & - & 61 & 119 & 145 & - & - \\
\hline$\Delta Q_{\mathrm{L}}\left[\mathrm{W} \mathrm{m}^{-2}\right]$ & - & -34 & -38 & -41 & - & - \\
\hline$Q_{\mathrm{H}}\left[\mathrm{W} \mathrm{m}^{-2}\right]$ & 8.7 & 1.3 & 14 & 22 & -1.5 & -4.4 \\
\hline$Q_{\mathrm{E}}\left[\mathrm{W} \mathrm{m}^{-2}\right]$ & $12^{\mathrm{c}}$ & 9.7 & 40 & 44 & $15^{\mathrm{c}}$ & 19 \\
\hline$Q_{\mathrm{G}}\left[\mathrm{W} \mathrm{m}^{-2}\right]$ & 18 & 14 & 15 & 20 & 6 & 0.5 \\
\hline$Q_{\mathrm{G}, \text { sensible }}\left[\mathrm{W} \mathrm{m}^{-2}\right]$ & 17 & 13 & 5 & 9 & 6 & 4 \\
\hline$Q_{\mathrm{G}, \text { latent }}\left[\mathrm{W} \mathrm{m}^{-2}\right]$ & 1 & 1 & 10 & 11 & 0 & -3.5 \\
\hline$E_{\text {melt }}\left[\mathrm{MJ} \mathrm{m}^{-2}\right]$ & 19 & 19 & - & - & - & - \\
\hline$C\left[\mathrm{~W} \mathrm{~m}^{-2}\right]$ & -1.7 & -3 & 12 & 18 & -12.5 & -10.1 \\
\hline$Q_{\mathrm{H}} / Q_{\text {net }}$ & 0.20 & 0.05 & 0.17 & 0.21 & -0.21 & -0.88 \\
\hline$Q_{\mathrm{E}} / Q_{\mathrm{net}}$ & $0.27^{\mathrm{c}}$ & 0.36 & 0.49 & 0.42 & $2.14^{\mathrm{c}}$ & 3.80 \\
\hline$Q_{\mathrm{G}} / Q_{\mathrm{net}}$ & 0.41 & 0.52 & 0.20 & 0.19 & 0.86 & 0.10 \\
\hline$C / Q_{\text {net }}$ & -0.04 & -0.11 & 0.15 & 0.17 & -1.79 & -2.02 \\
\hline$Q_{\mathrm{H}} / Q_{\mathrm{E}}$ & 0.73 & 0.13 & 0.35 & 0.50 & -0.10 & -0.23 \\
\hline$T_{\text {surf }}\left[{ }^{\circ} \mathrm{C}\right]$ & -3.8 & -6.9 & 10.5 & 9.2 & 3 & 1.2 \\
\hline$T_{\text {air }}\left[{ }^{\circ} \mathrm{C}\right]$ & -4.7 & -6.9 & 9.2 & 8.2 & 2.6 & 1.6 \\
\hline $\mathrm{RH}[\%]$ & 84 & 84 & 84 & 84 & 88 & 87 \\
\hline$P[\mathrm{~mm}]$ & SWE: 60 & SWE: 57 & 58 & 100 & 49 & 21 \\
\hline
\end{tabular}

${ }^{a}$ Radiation values measured with the NR-Lite sensor.

b Values obtained with the four-component CNR1 sensor.

${ }^{\mathrm{c}}$ Modeled values of latent heat flux.

in all energy balance components (Fig. 4). The turbulent sensible heat flux ranges from -30 to $20 \mathrm{~W} \mathrm{~m}^{-2}$ during the pre-melt period and follows the course of the net radiation. With the onset of the melt period, persistent negative sensible heat fluxes are observed, which appear to be partly decoupled from the net radiation (Fig. 4). This relation indicates that both the turbulent sensible heat fluxes and the incoming short-wave radiation contribute to the snow melt. As soon as larger snow-free areas are present, the sensible heat flux becomes positive and rapidly exceeds $40 \mathrm{~W} \mathrm{~m}^{-2}$. After the snow cover has disappeared entirely at the end of May, the sensible heat flux reaches peak values of $90 \mathrm{~W} \mathrm{~m}^{-2}$. A similar evolution is observed for the latent heat flux, which is between 0 and $10 \mathrm{~W} \mathrm{~m}^{-2}$ before the onset of snow melt and quickly increases to values of $50 \mathrm{~W} \mathrm{~m}^{-2}$ during the first snow melt event. After the snow cover is completely melted, the latent heat flux exceeds $100 \mathrm{~W} \mathrm{~m}^{-2}$ and has an average value of $35 \mathrm{~W} \mathrm{~m}^{-2}$ during the last ten spring days of 2008. This heat flux corresponds to a total energy turnover of $30 \mathrm{MJ} \mathrm{m}^{-2}$ or a total amount of evaporated water of $12 \mathrm{~mm}$. As the snowwater equivalent of 2008 amounts to approximately $57 \mathrm{~mm}$, about $20 \%$ of the snow cover sublimate or evaporate during the last days of the spring period. This high latent heat flux relate to the period when the tundra surface is characterized by ponding melt water above the frozen soil. After this period the snow cover effectively supplies $45 \mathrm{~mm}$ to the summertime water budget, which is about $20 \%$ of the total precipitation after snow melt (1 June-30 September).

The atmospheric stratification is reflected in the stability parameter $\zeta$, which is almost zero during neutral conditions, larger than zero for stable, and smaller than zero for unstable atmospheric stratifications. During the pre-melt period, the atmospheric stratification changes frequently between stable and unstable conditions (Fig. 4). At this time, neutral stratifications occasionally occur together with wind speeds of over $2 \mathrm{~m} \mathrm{~s}^{-1}$. At the beginning of the melt period, the wind speed is generally high and the atmospheric stratification becomes neutral (Fig. 4). The average ground heat flux during 


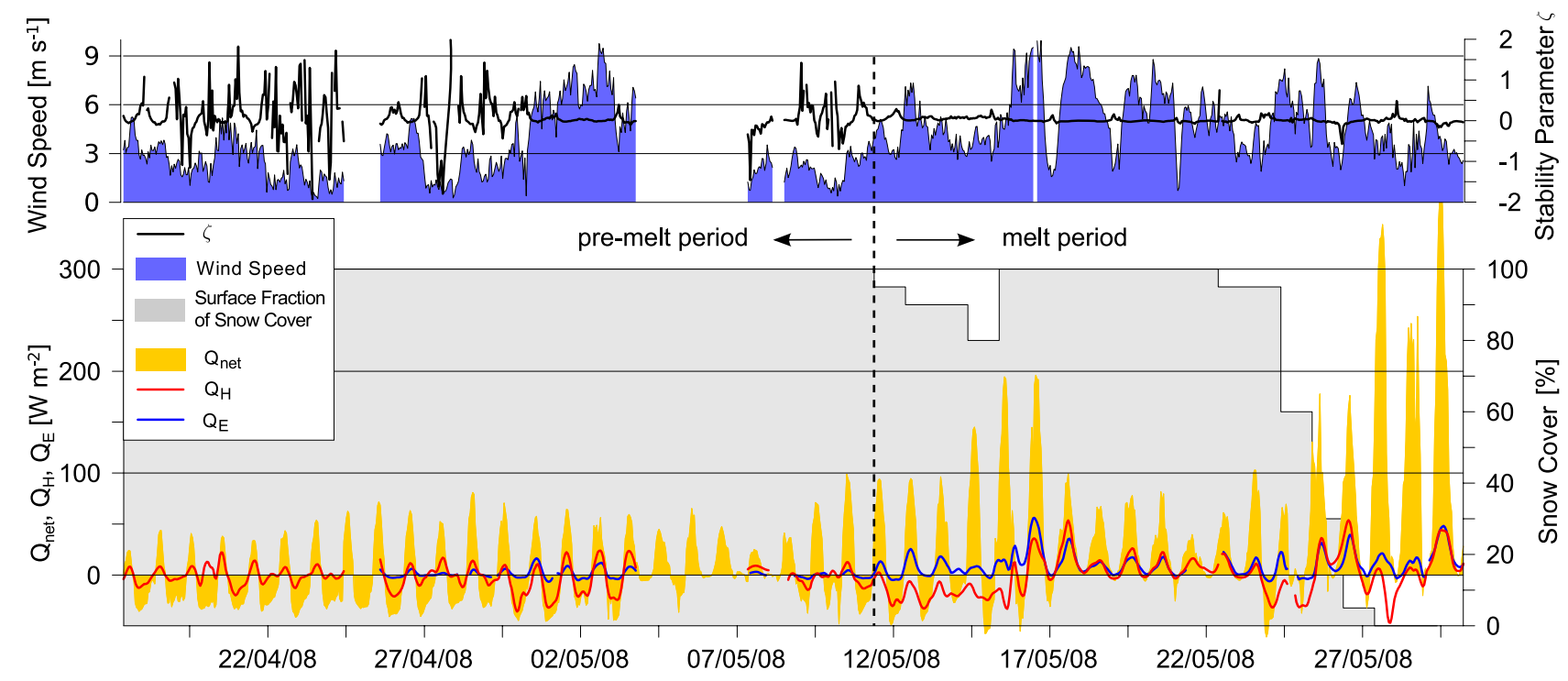

Fig. 4. Net radiation, sensible heat flux, latent heat flux, wind speed, atmospheric stability parameter $\zeta$, and approximate fraction of the snow-covered area (in gray) during spring 2008. The energy balance is strongly related to the evolution of the snow melt. Wind speed increases during the melt period, and atmospheric stratification is neutral. Varying atmospheric conditions are observed in the pre-melt period.

the spring period is remarkably positive and is dominated by the storage of sensible heat in both years (Table 2), which is associated with a steady warming of the deeply frozen soil. In general soil temperatures are very low. At the depth of the zero annual amplitude (approximately $15 \mathrm{~m}$ ), the soil temperature is found to be about $-10^{\circ} \mathrm{C}$. A closer look at the evolution of the ground heat storage (Fig. 5) reveals faster soil warming in early spring 2007. This difference in the evolution of the ground heat budget compared to 2008 is related to warmer air and snow surface temperatures, but relatively cold soil temperatures in early spring 2007 (Table 2). In both years, the amplitude of the ground heat flux through the snow cover typically ranges from -20 to $20 \mathrm{~W} \mathrm{~m}^{-2}$ during the premelt period and is thus in the range of the turbulent sensible heat fluxes.

\subsubsection{Summer (1 June-31 August)}

The summer period is characterized by a strong short-wave radiative forcing, a snow-free surface, day time temperatures well above freezing point, and thawing of the active layer (Table 2). The thaw depths during summer range from 0.40 to $0.50 \mathrm{~m}$. Polar day conditions last until $7 \mathrm{Au}-$ gust, featuring high values of incoming short-wave radiation. Daily averages of incoming short-wave radiation often exceed $300 \mathrm{~W} \mathrm{~m}^{-2}$ under clear-sky conditions and can be as low as $20 \mathrm{~W} \mathrm{~m}^{-2}$ under overcast situations, which occur frequently. The reduced solar radiation during cloudy conditions is partly compensated by increased long-wave radiation. The daily average of incoming long-wave radiation typically ranges from $280 \mathrm{~W} \mathrm{~m}^{-2}$ for clear-sky to
$380 \mathrm{~W} \mathrm{~m}^{-2}$ for cloudy situations. The daily average of emitted long-wave radiation varies between $330 \mathrm{~W} \mathrm{~m}^{-2}$ and $420 \mathrm{~W} \mathrm{~m}^{-2}$, which corresponds to average surface temperatures between 3 and $20^{\circ} \mathrm{C}$. Consequently, the net long-wave losses frequently exceed $100 \mathrm{~W} \mathrm{~m}^{-2}$ during clear-sky conditions, while they are almost zero during overcast situations. The average summer net radiation for 2007 is slightly higher than for 2008 (Fig. 3), which is most likely caused by differences in cloudiness. This is also confirmed by the precipitation rates, which are doubled during the early summer period of 2008.

In both years, unstable stratifications $(\zeta<0)$ occur frequently during the day, but usually do not last longer than $12 \mathrm{~h}$. The nights are dominated by neutral stratifications $(\zeta \approx 0)$, while stable atmospheric conditions $(\zeta>0)$ are only occasionally observed under calm conditions with highly negative values of the net radiation. The turbulent heat fluxes constitute important components in the summertime energy balance. About 20 to $30 \%$ of the net radiation is consumed by turbulent sensible heat flux, while the latent heat flux amounts to about 40 to $50 \%$ (Fig. 3, Table 2). The turbulent heat fluxes show a strong diurnal cycle and frequently exceed $130 \mathrm{~W} \mathrm{~m}^{-2}$ for the sensible and $150 \mathrm{~W} \mathrm{~m}^{-2}$ for the latent heat flux during the day. During the night, negative sensible heat fluxes of around $-20 \mathrm{~W} \mathrm{~m}^{-2}$ are observed, while negative latent heat fluxes (dew formation) occur only occasionally. Such events are then associated with highly negative net radiation and low surface temperatures, as they occur at the end of the summer section. We describe an exemplary period during late summer 2008 in Fig. 6, which illustrates the typical diurnal cycle of the heat flux components forced 

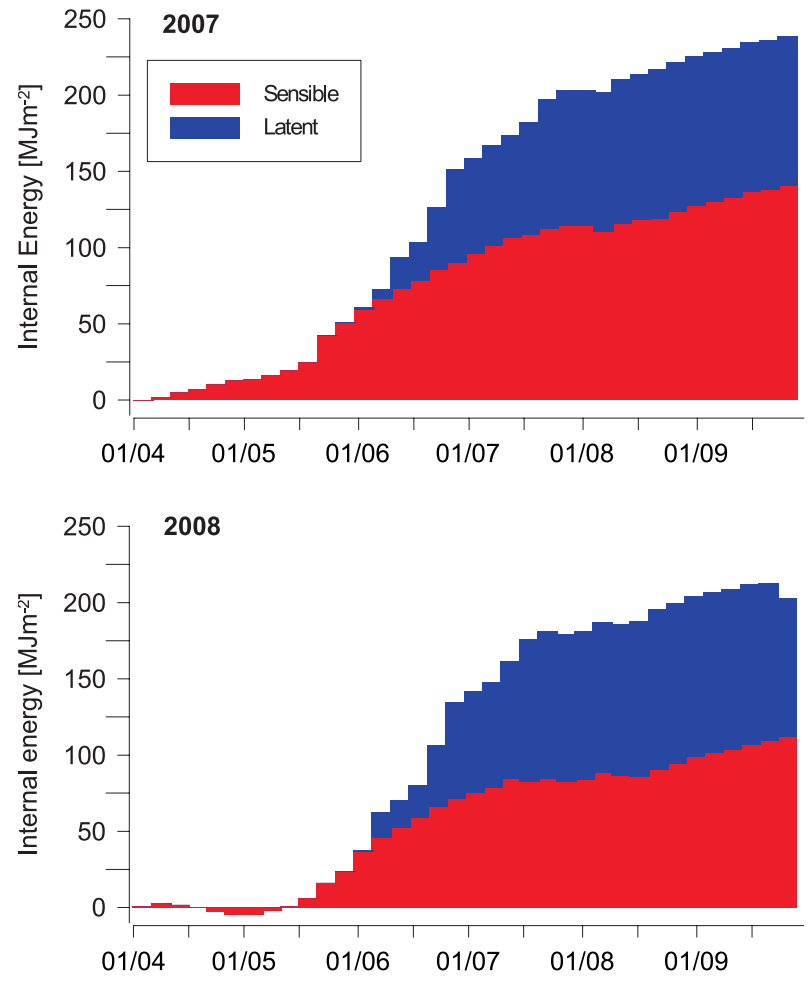

Fig. 5. Internal energy of the soil over the entire observation period in 2007 and 2008. In both years, $0 \mathrm{MJ} \mathrm{m}^{-2}$ is defined as the internal energy of the soil on 1 April. Soil temperatures from 2007 are colder in spring, and the air temperatures are warmer, which explains the increased heat storage at the beginning of the period. Towards the end, soil temperatures are almost equal.

by the incoming solar radiation. The wind speed appears to be associated with a diurnal pattern (Fig. 6), which indicates enhanced turbulent heat exchange during the day and lowered turbulence during the night. No dependence on the wind direction during day time is detected. The wind directions show a slight dominance in NW and SSE direction in 2007, while a slight dominance in NW and ESE direction is observed in 2008. For both years, we measure a distinct influence of the wind direction on the air temperature which is on average $6^{\circ} \mathrm{C}$ colder during north winds. However, a corresponding influence of the wind direction is found neither on $Q_{\mathrm{H}} / Q_{\text {net }}$ nor on $Q_{\mathrm{E}} / Q_{\text {net }}$.

For both years, the average Bowen ratio, $Q_{\mathrm{H}} / Q_{\mathrm{E}}$, is below one, indicating high rates of evapotranspiration. During the summertime periods, the evaporated water amounts to about $70 \mathrm{~mm}$ in 2007 (12 July-23 August) and about $100 \mathrm{~mm}$ in 2008 (7-8 July; 29 July-30 August). It is worth noting that the amount of evaporated water roughly equals the precipitation measured in the corresponding periods (Table 2). However, the inter-annual comparison is not meaningful, due to the different length of the observation periods.

An inter-annual comparison of turbulent heat fluxes is feasible using modeled latent heat fluxes (Appendix D) to fill gaps in the measured time series (Fig. 2). Inter-annual differences in the turbulent heat fluxes occur during the early and mid summer period (Fig. 3). During this time, the net radiation in 2008 is depressed, most likely due to increased cloudiness. In accordance with the net radiation, lower sensible heat fluxes are observed in 2008 . In contrast, the latent heat fluxes are slightly higher during early summer 2008, which may be attributed to the higher precipitation (Fig. 3). In both years, the ground heat flux is an important term in the summertime energy balance, which consumes about 20 to $25 \%$ of the available net radiation. About $60 \%$ of the energy provided by the ground heat flux is consumed by active layer thawing, while the remaining fraction leads to a warming of the soil (Fig. 5). During the summer months maximum thaw depths between 0.40 and $0.50 \mathrm{~m}$ are reached. The shallow thaw depth causes strong temperature gradients in the active layer, which enhances the ground heat flux. The ground heat flux shows a strong diurnal cycle and frequently exceeds $50 \mathrm{~W} \mathrm{~m}^{-2}$ during the day (Fig. 6), while negative ground heat fluxes are observed only occasionally during clear night skies.

\subsubsection{Fall (1-30 September)}

The fall period is characterized by steadily decreasing air and surface temperatures. This period is further characterized by the onset of freezing and occasional snow fall, but a continuous snow cover does not form yet. In each year, the fall period starts with air and surface temperatures well above the freezing point and ends with temperatures around $0^{\circ} \mathrm{C}$. Only occasional freezing events are observed during the fall period for 2007, while sustained freezing occurred in 2008. The inter-annual difference in the temperature evolution is reflected in the average air and surface temperatures, as well as in the ground heat fluxes (Table 2). In 2008, the entire active layer already approaches temperatures of $0{ }^{\circ} \mathrm{C}$ at 17 September, but warms again for one week, before the soil temperature finally reaches the zero-curtain around 25 September. In contrast, the soil temperature in 2007 never enters the zero-curtain during the fall period. The average ground heat flux in fall 2007 remains positive, while it is almost zero in 2008 (Table 2). In both years, a soil warming in depths between 1 and $10 \mathrm{~m}$ leads to $Q_{\mathrm{G} \text {,sensible }}>0$. This warming of the deeper soil layers is compensated by the release of latent heat in the active layer due to initial freezing in 2008 (Table 2). The average net radiation is reduced, but still positive in both years and features a distinct diurnal cycle with daytime values on the order of $100 \mathrm{~W} \mathrm{~m}^{-2}$. A negative net radiation on the order of $-50 \mathrm{~W} \mathrm{~m}^{-2}$ is frequently observed during the nights in 2008 , which occurs only sporadically in 2007 . The reduced radiative losses during the nights and the higher amount of precipitation in fall 2007 indicate increased cloudiness (Table 2). In both years, the average sensible heat flux is negative and thus warms the surface, but it is more negative in 2008. This is in accordance with 


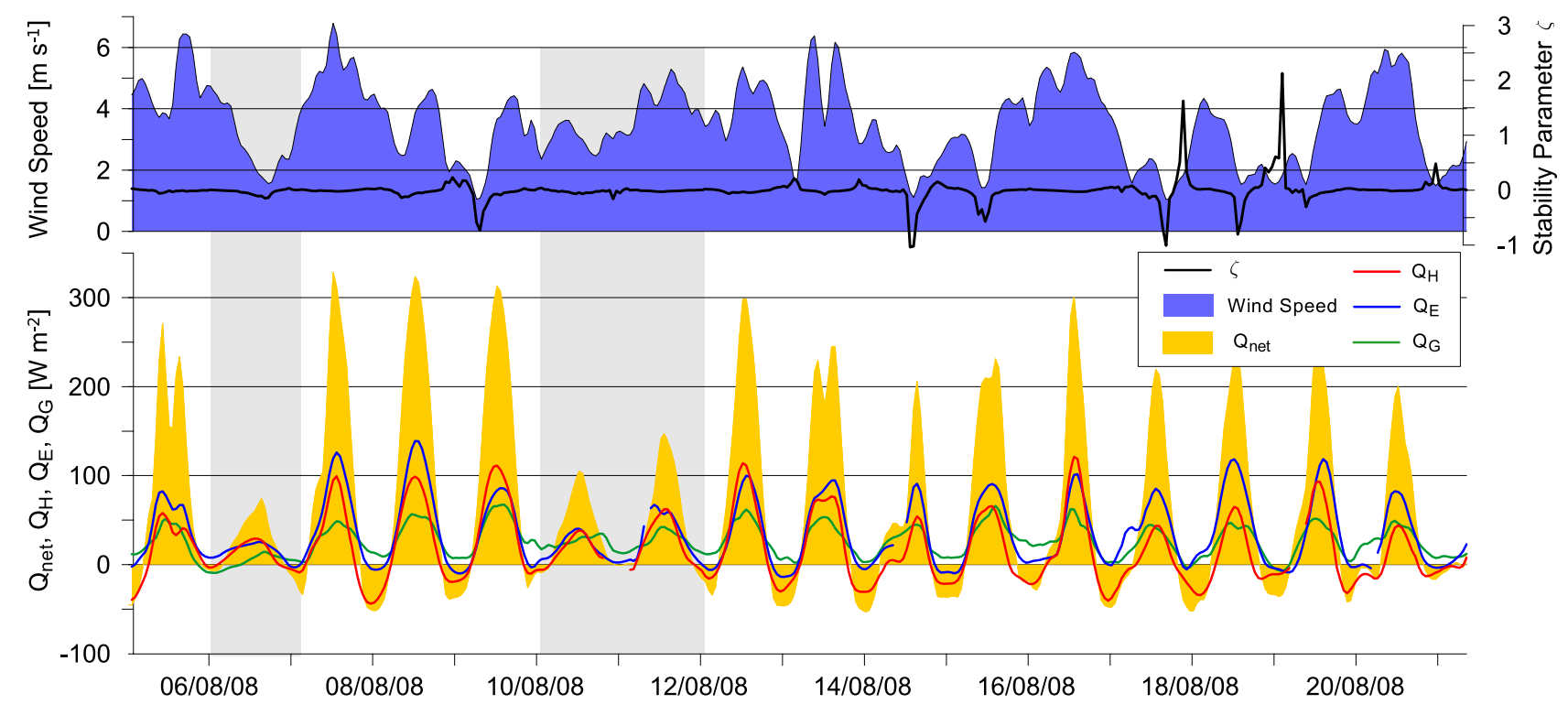

Fig. 6. Sample heat fluxes, wind speed, and stability parameter during late summer 2008, with overcast periods marked in gray.

pronounced negative gradients of the night time air temperatures, which have been measured in fall 2008. Despite the reduced net radiation, the latent heat fluxes still play a dominant role in the surface energy balance (Fig. 3). In both years the latent heat flux exceeds the net radiation. Hence, the required energy for evapotranspiration must be delivered partly by the other energy balance components. According to the heat flux directions, this can only be assigned to the sensible heat flux.

In both years, the atmospheric stratification is dominated by neutral conditions, corresponding to high wind speeds. However, stable stratifications occasionally occur during calm nights, when the net radiation becomes highly negative and strongly negative gradients in the near surface air temperature arise. Such events occur more frequently in 2008.

\subsection{Spatial variability of the surface energy balance}

The polygonal tundra features pronounced micro-scale heterogeneity, particularly regarding to the surface soil moisture and vegetation cover: the elevated polygonal rims are typically covered with dry mosses, while the lowered centers are filled with wet peat soils or shallow ponds. Therefore, spatial differences in the surface energy balance may occur over scales of a few meters. In accordance with the surface classification displayed in Fig. 1, we distinguish wet, dry and water surfaces.

During the summer period, spatially distributed measurements of the albedo yield values of approximately 0.2 for dry and 0.15 for wet tundra surfaces. The latter value is consistent with the average albedo of 0.14 obtained from long-term measurements of incoming and outgoing short-wave radia- tion (CNR1 sensor) over a wet tundra spot. For the summer period, this albedo difference leads to a lower net short-wave radiation $\Delta Q_{\mathrm{S}}$ at the dry surfaces of about $5 \mathrm{~W} \mathrm{~m}^{-2}$, with a maximum of up to $25 \mathrm{~W} \mathrm{~m}^{-2}$ during local noon under clearsky conditions. Furthermore, strong spatial differences in the surface temperature occur under such conditions, with the dry surfaces being 5 to $10^{\circ} \mathrm{C}$ warmer than the wet surfaces. As this corresponds to a lower net long-wave radiation at the dry surfaces of 25 to $50 \mathrm{~W} \mathrm{~m}^{-2}$, the net radiation may be up to $75 \mathrm{~W} \mathrm{~m}^{-2}$ lower at dry surfaces than at wet surfaces, in case of clear-sky conditions and local noon. During nights with clear-sky conditions, the differences in surface temperature are inverted, with increased surface temperatures and thus increased outgoing long-wave radiation at the wet locations. During overcast periods, the spatial differences in surface temperature largely vanish. As such cloudy conditions are frequent and the day and night differences of the surface temperature under clear-sky conditions cancel at least partly, the spatial differences of the surface temperature are reduced to below $1{ }^{\circ} \mathrm{C}$ for longer averaging periods, resulting in differences in the average net long-wave radiation of less than $5 \mathrm{~W} \mathrm{~m}^{-2}$. Thus, we conclude that the spatial differences of the average net radiation between wet and dry surfaces are smaller than $10 \mathrm{~W} \mathrm{~m}^{-2}$ during the summer period.

Pronounced differences in the net radiation are measured between the tundra soil and the polygonal pond (Fig. 7). During the pre-melt period, the net radiation observed at the polygonal pond stays at a constant 5 to $10 \mathrm{~W} \mathrm{~m}^{-2}$ lower than the tundra surface. After the melt period, the measurements show a higher net radiation at the water body of the order of 20 to $30 \mathrm{~W} \mathrm{~m}^{-2}$, which gradually diminishes over the course of the summer and fall periods (Fig. 7). During spring, the 


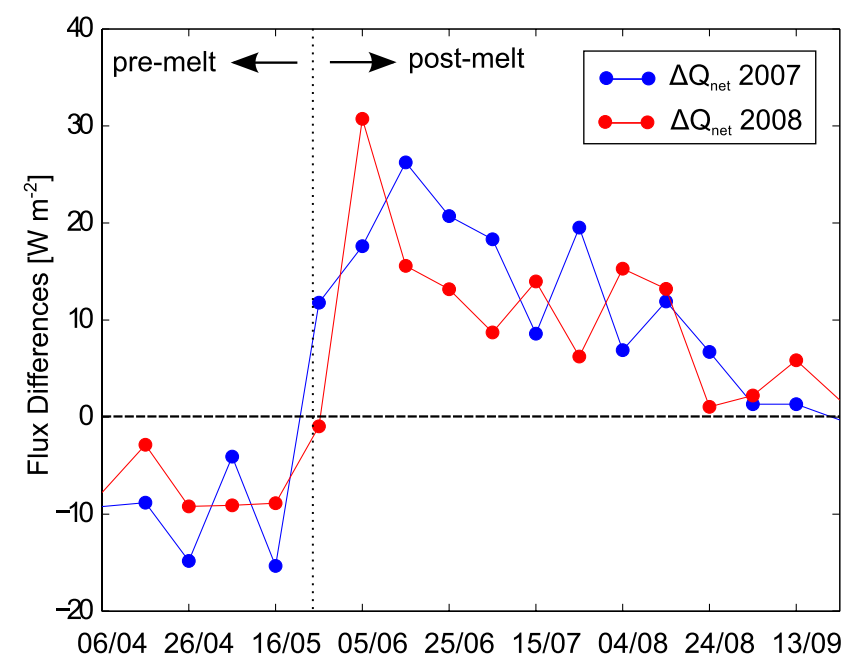

Fig. 7. Differences between the net radiation measured at the pond and the tundra surface $\Delta Q_{\text {net }}$ during the observation periods in 2007 and 2008.

differences might be explained by a higher albedo or increased surface temperatures at the frozen pond. During the summer period, similar surface temperatures are observed for the water body and the tundra surface. Hence, the differences in net radiation are most likely explained by a lower albedo of the water body.

Spatial differences between wet and dry surfaces in the turbulent heat fluxes are investigated using the stationary eddy station and the second location of the mobile eddy system (Fig. 1). On average the second mobile eddy station has a $20 \%$ higher fraction of dry surface areas than the reference location according to the footprint analysis. The simultaneous measurements at each location indicate that moderate spatial differences of around $20 \mathrm{~W} \mathrm{~m}^{-2}(10-20 \%)$ can be expected for the sensible and latent heat fluxes under conditions of high radiative forcing $\left(Q_{\text {net }}>200 \mathrm{~W} \mathrm{~m}^{-2}\right)$ (Fig. 8), which occur only sporadically during the summer period. Assuming that the dependencies between the net radiation and the differences in the turbulent heat fluxes displayed in Fig. 8 (which have been evaluated for a period of one week) can be generalized for the entire summer period, we can calculate the average differences between both measurement locations for the entire summer period from the distribution of the net radiation (see histogram in Fig. 8). For the summer period 2008, the calculated average sensible heat flux is $7 \pm 7 \mathrm{~W} \mathrm{~m}^{-2}$ higher at the mobile station, while the average latent heat flux is $8 \pm 10 \mathrm{~W} \mathrm{~m}^{-2}$ lower. Based on these results, we calculate the heat flux contributions of wet and dry surfaces using fractional unmixing. The average latent heat flux $Q_{\mathrm{E}}$ at location I (stationary station) and II (mobile station) can be evaluated as

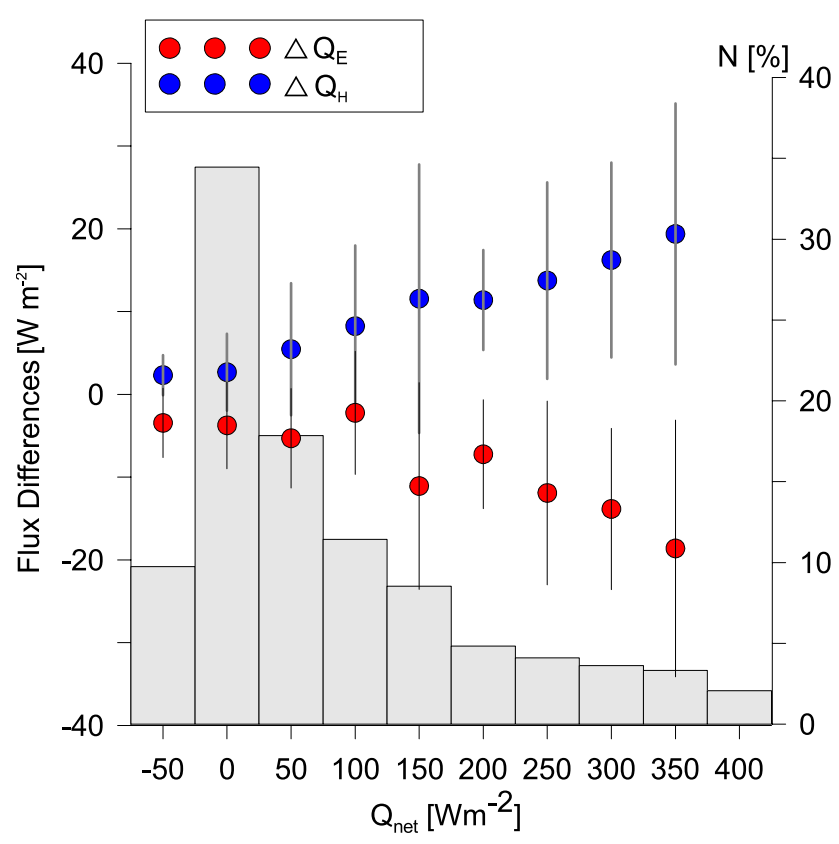

Fig. 8. Differences of sensible $\Delta Q_{\mathrm{H}}$ and latent heat fluxes $\Delta Q_{\mathrm{E}}$ as measured between the stationary station and the second location of the mobile eddy system (7-14 August 2008). The histogram depicts the distribution of net radiation values over the entire summer period (7 June-30 August 2008).

$Q_{\mathrm{E}}^{\mathrm{I}}=f_{\mathrm{dry}}^{\mathrm{I}} Q_{\mathrm{E}, \mathrm{dry}}+f_{\mathrm{wet}}^{\mathrm{I}} Q_{\mathrm{E}, \mathrm{wet}}$,

$Q_{\mathrm{E}}^{\mathrm{II}}=f_{\mathrm{dry}}^{\mathrm{II}} Q_{\mathrm{E}, \mathrm{dry}}+f_{\mathrm{wet}}^{\mathrm{II}} Q_{\mathrm{E} \text {,wet }}$.

Hereby, $Q_{\mathrm{E} \text {,dry }}$ is the average latent heat flux originating from dry surfaces, $Q_{\mathrm{E} \text {,wet }}$ is the average latent heat flux originating from wet surfaces and ponds, and $f_{\text {dry }}$ and $f_{\text {wet }}$ are the fractions of dry and wet (including pond) surfaces in the average flux source area at location I and II, respectively. According to the footprint analysis, the stationary location features $f_{\text {dry }}^{\mathrm{I}} \approx 0.6$ and $f_{\text {wet }}^{\mathrm{I}} \approx 0.4$, while the mobile location consists of $f_{\text {dry }}^{\mathrm{II}} \approx 0.8$ and $f_{\text {wet }}^{\mathrm{II}} \approx 0.2$. Note that performing this procedure for average fluxes and average footprint areas is a good approximation, as the fractions of wet and dry areas within the footprints do not vary strongly $( \pm 5 \%)$ over time. The calculated fluxes reveal that dry and wet surfaces are distinctly different sources for sensible and latent heat fluxes (Fig. 9): at dry surfaces, about the same amount of energy is attributed to sensible and latent heat fluxes (Bowen ratio $Q_{\mathrm{H}} / Q_{\mathrm{E}}$ of 1.29), while the wet surfaces feature a strong dominance of the latent heat flux (Bowen ratio 0.02) with an almost negligible contribution of the sensible heat flux. The latter is in good agreement with the small difference, that is usually observed between the surface and air temperatures for the wet areas. With declining net radiation in the fall period, almost no differences in sensible and latent heat fluxes are measured between the locations of the stationary and the mobile system. 


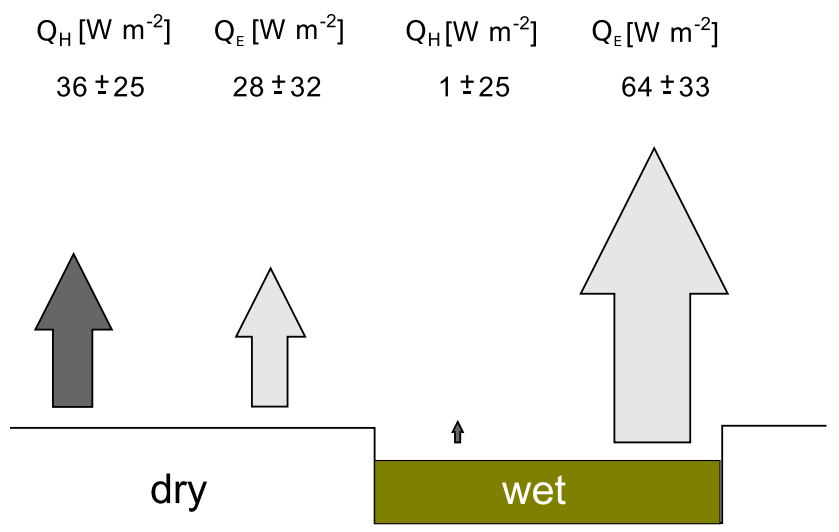

Fig. 9. Sensible $Q_{\mathrm{H}}$ and latent heat fluxes $Q_{\mathrm{E}}$ at wet and dry surfaces during summer 2008. The values are estimated from the eddy covariance measurements of the stationary and mobile eddy covariance systems. The areas of the arrows are scaled according to the heat flux values.

\section{Discussion}

\subsection{Measurement errors and energy balance closure}

During the entire observation period, an unclosed energy balance is found for both half-hourly values and long-term averages (Table 2).

Following the classification of Westermann et al. (2009), we loosely distinguish four different categories of errors affecting long-term energy balance closure: (I) the measurement accuracy of the applied instrumentation; (II) errors inherent in the method of measurement; (III) the uncertainty of the parameters used to calculate the ground heat flux; (IV) errors resulting from mismatching footprint areas:

I. Only a systematic offset in the instrument accuracy can give rise to the observed closure terms of the long-term averages (Table 2), since random measurement errors would be greatly reduced by the averaging procedure. The accuracies of the net radiation sensors are expected to be $10 \%$ for the CNR1 and $20 \%$ for the NR-Lite sensor (see Sect. 3). Consequently, the observed closure terms during spring are within the possible error margins of the net radiation, while the closure terms exceed the uncertainty of the net radiation measurements during all the other periods.

II. When high-frequency measurements of the water vapor concentration are not available, the sensible heat flux $Q_{\mathrm{H}}$ is substituted with the buoyancy flux $Q_{\mathrm{HB}}$. While the maximum bias of about $15 \%$ of the measured buoyancy flux (see Sect. 3.2) might explain the closure terms during both spring periods, it cannot during fall 2007.

More general, the accuracy of the eddy covariance method is known to be limited under non-stationary conditions, which in a strict sense are rather the norm than the exception under normal atmospheric conditions (Inagaki et al., 1996; Foken, 2008). This can lead to a systematic underestimation of the true sensible and latent heat fluxes, which is reported to potentially exceed $25 \%$ of the measured values (Wilson et al., 2002). While the applied quality control (see Sect. 3.2) ensures minimum standards of our flux measurements, Mauder et al. (2006) report uncertainties of 15 to $20 \%$ on the turbulent fluxes for mid-latitudes using the same quality control scheme. In addition to the other uncertainties, this error could explain a large part of the closure term during summer when energy balance could be closed by increasing the magnitude of the turbulent fluxes. However, the large closure terms during the fall periods are still problematic, as they cannot be explained.

III. The uncertainty of the ground heat flux $Q_{\mathrm{G}}$ is mainly determined by the accuracy of the employed values for the thermal properties of the soil or the snow. The heat capacities $C_{\mathrm{h}}$ of soil and snow are inferred from soil component analysis, in situ soil moisture detection and snow-water equivalent measurements on the point scale. The thermal conductivity $K_{\mathrm{h}}$ is calculated by a fitting procedure, assuming purely conductive heat transfer and uniform composition of the considered soil or snow domain. Such idealized conditions do not exist in reality, which is reflected in the uncertainty of the determined thermal diffusivity values. Furthermore, both the heat capacity and the thermal conductivity are spatially variable, so that the employed values are associated with a considerable standard deviation inferred from measurements at multiple locations (Table 1). Therefore, the ground heat flux has a large relative uncertainty of around $30 \%$ (Sect. 3.3). Such uncertainty in the ground heat flux might explain the closure term in spring but not during the other periods (Table 2).

IV. The components of the surface energy balance are measured at different spatial scales in this study: the ground heat flux is inferred from point measurements of soil temperatures and moisture, while the radiation sensors provide an average over surface areas of up to a few dozens of square meters, which is still only a fraction of the even larger footprint area of the eddy covariance system. An unclosed surface energy balance is at least to some degree inevitable, if e.g. the point measurements are not conducted at sites "representative" for the footprint area of the eddy covariance system. Therefore, it is very likely that considerable errors are induced by spatial inconsistencies: the ground heat fluxes are only derived at water-saturated sites due to the high uncertainty in the thermal properties of dry soils. The net radiation sensors are pointed towards wet surfaces, but measurements are also influenced by the surrounding dry surfaces, while the eddy covariance system averages over varying fractions of wet and dry surfaces. 
In the results section, we demonstrated that both the net radiation and the turbulent heat fluxes are affected by surface heterogeneities resulting in spatial heat flux differences on the order of several $\mathrm{W} \mathrm{m}^{-2}$ (Fig. 4.2). This error source sometimes becomes obvious during summer nights with clear-sky conditions, when the direction of the ground heat flux at the wet soils stays positive, and other components of the energy balance require zero to negative ground heat fluxes (see Sect. 4.1.2 and Fig. 6).

Despite of the difficult measurement conditions in the Arctic the magnitude of the observed closure terms is in range of the closure terms found in a number of carefully designed field experiments (overview in Foken, 2008). This gives us confidence that the true magnitude of the components of the surface energy balance is adequately represented in this study.

\subsection{Controlling factors of the surface energy balance}

Three factors can be identified that determine the characteristics of the surface energy balance at the investigated wet tundra landscape. The determining factors are (i) the snow cover, (ii) the presence or absence of a cloud cover and (iii) the presence of cold permafrost leading to a strong gradient of the soil temperatures.

i. Although the snow cover is only shallow at the study site, it has strong implications for the surface energy balance. Firstly, the albedo of the snow cover is about a factor of four higher than the albedo of the snow-free tundra surface. Secondly, the thermal conductivity of snow is about a factor of two lower than the thermal conductivity of frozen peat. The second point is of particular importance during winter, when the low thermal conductivity of the snow cover impedes the release of energy from the ground and leads to a reduced ground heat flux (Zhang, 2005; Ling and Zhang, 2007). During spring, however, the soil has already cooled, so that the lower thermal conductivity of the snow is of minor importance for the ground heat budget and the surface energy balance (Goodrich, 1982). In contrast, the high albedo of the snow has a strong impact on the surface energy budget during the spring period, when the incoming short-wave radiation already features high values. At the study site, the snow cover effectively reduces the net short-wave radiation until the beginning of the polar day period (6 May). The melting of the snow cover with the associated change in surface albedo triggers a sudden change from a winter to a summer surface energy balance, so that the timing of snow melt is a critical point in the annual course of the surface energy balance. In both investigated years, the timing of the snow melt is almost identical. Iijima et al. (2007) point out that snow cover disappearance in eastern Siberia is strongly related to the attenuation of the Siberian High with subsequent advection of warm and moist air masses from the west. According to the distinct contribution of sensible atmospheric heat flux to the snow melt, our measurements indicate the presence of warm air masses. However, the short-wave radiation is still the dominant factor driving the snow melt.

ii. The large-scale advection of warm air is usually related to increased cloudiness, which alters the net radiation and thus the entire surface energy balance. During the spring period, our results indicate that the observed inter-annual differences in the ground temperatures are caused by different air temperatures, which are presumably related to the lager scale atmospheric advection processes. During the summer months, the net radiation is reduced for cloud-covered skies, which in turn leads to surface cooling. According to our measurements, this mainly affects the magnitude of turbulent heat fluxes. While the surface temperature is lower under cloudy conditions, this only marginally decreases the strong temperature gradient in the soil, so that the impact of clouds on the ground heat flux is minor. Hence, the thawing dynamics of the active layer is only marginally affected by changed cloudiness. During the fall period, the contrary effect of a cloud cover is observed, as clouds reduce the long-wave radiative losses, leading in turn to increased surface temperatures. The impact of clouds on the ground heat budget is observed to be largest during the fall season, when presumably increased cloudiness delays the refreezing process in 2007, while the average air temperatures are similar. This twofold influence of the cloud cover on the net radiation in the Arctic is confirmed in several studies (Curry et al., 1996; Intrieri et al., 2002; Shupe and Intrieri, 2004).

iii. During the entire observation period, the ground heat flux is a large component of the surface energy balance. About $20 \%$ of the net radiation is stored as latent and sensible heat in the ground, which is in the upper range of the typical values reported for other arctic permafrost regions (Boike et al., 1998; Lynch et al., 1999; Eugster et al., 2000; Westermann et al., 2009). The high contribution of ground heat flux to surface energy balance is caused by the cold permafrost temperatures, the shallow active-layer depth and the large annual surface temperature amplitude, which is related to the continental climate conditions. During the summer period, the sensible heat storage makes up about $50 \%$ of the entire ground heat flux. As already shown by Romanovsky and Osterkamp (1997), this limits the value of the widely used Stefan equation, which evaluates the active layer dynamics by assuming the ground heat flux to be used entirely for thawing. In general, 
the high contribution of the ground heat flux to the surface energy balance indicates that it must be considered as an important factor in larger-scale model approaches. This is different to the mid latitudes, where the average ground heat flux usually ranges between 0 to $6 \mathrm{~W} \mathrm{~m}^{-2}$, which is about $5 \%$ of the net radiation and hence is often considered to be of less importance in modeling and validation studies (e.g., Baker and Baker, 2002; Boone et al., 2009). It should be carefully checked, whether the parameterizations of soil thermal processes (which have been developed in and for the mid-latitudes) employed in current large-scale circulation models can adequately account for the prominent role of the ground heat flux in permafrost areas. This issue is of particular importance, as permafrost areas with continental climate, where high ground heat flux can be expected, occupy vast areas in the Arctic. This improvement of modeling results by employing more realistic parameterizations of the soil processes has been outlined in a number of studies (e.g., Peters-Lidard et al., 1998; Cox et al., 1999; Viterbo et al., 1999; Pitman, 2003).

\subsection{Spatial differences of the surface energy balance}

In this study, spatial differences in the surface energy balance are observed for (i) the net radiation and (ii) the turbulent heat fluxes.

i. The measured differences in the net radiation between wet and dry surfaces are on average less than $10 \mathrm{~W} \mathrm{~m}^{-2}$. More pronounced spatial differences in the radiation balance are measured between the tundra and the pond. The net radiation of the investigated pond is slightly lower in frozen and snow-covered conditions during spring, but higher during the summer months. The pond investigated in this study indicates that small shallow water bodies can have influence on the net radiation in polygonal tundra landscapes, as they are common landscape elements. While the impact of larger water bodies on the arctic climate conditions has been investigated (Krinner, 2003; Rouse et al., 2005; Krinner and Boike, 2010), such small water bodies have not received similar attention. It is thus highly desirable to evaluate the impact of small water bodies on the larger-scale surface energy balance, particularly since such microscale landscape structures usually remain undetected in remote sensing applications and are neglected in model approaches.

ii. Our measurements reveal differences in sensible and latent heat fluxes according to variations in the fractions of dry and wet surfaces in the footprint areas (Fig. 8). The observed spatial variations are caused by the smallscale surface-temperature differences that exist between wet and dry surfaces. As the temperature difference between wet and dry surfaces depends on the net radia- tion, differences in the turbulent fluxes are most pronounced during clear-sky situations, which occur only occasionally during the summer period. For the summertime average, sensible and latent heat fluxes have been found to be of similar magnitude at dry locations, while at wet surfaces the turbulent heat flux is almost completely determined by evapotranspiration (Fig. 9). Hence, the polygonal surface structures strongly affect the Bowen ratio at the landscape scale. This could be of great importance when discussing surface drying or wetting due to water table changes. Transforming the wet polygonal centers to surfaces similar to the polygonal rims, would at least increase the Bowen ratio by a factor of two which in turn could lead to an increased near surface air temperature.

\subsection{Comparison to other arctic sites}

Only few studies on the surface energy balance exist for arctic regions, most of which only cover short periods or do not include all components of the energy balance. The most comprehensive summary for a number of sites in the Arctic and Subarctic (except Siberia) is given by Eugster et al. (2000). In addition, studies on the surface energy balance have been published for Alaska (Ohmura, 1982; Harazono et al., 1998; Mendez et al., 1998; Lynch et al., 1999; Vourlitis and Oechel, 1999; Chapin et al., 2000), Greenland (Soegaard et al., 2001), Svalbard (Harding and Lloyd, 1998; Westermann et al., 2009) and Siberia (Boike et al., 1998; Kodama et al., 2007). Since most of these studies only provide flux values for the summer season (JulyAugust), a meaningful comparison is only possible for this time. Here, we use the averages of the summer period in 2007.

The Bowen ratio of around $0.35-0.5$ observed in this study for polygonal tundra in Siberia demonstrates the high evapotranspiration rates of a typical wetland and is well within the given range from other arctic wetland locations. The total evapotranspiration rate of $1.4 \mathrm{~mm} \mathrm{~d}^{-1}$ falls between the lower ranges reported from Svalbard $\left(\approx 1 \mathrm{~mm} \mathrm{~d}^{-1}\right)$ (Lloyd et al., 2001; Westermann et al., 2009) and higher values for wetland sites in Greenland $\left(1.5 \mathrm{~mm} \mathrm{~d}^{-1}\right)$ and Alaska (1.5 to $2.3 \mathrm{~mm} \mathrm{~d}^{-1}$ ).

With a fraction of $20 \%$ of the net radiation, the ground heat flux observed at the study site is among the largest values reported for Alaskan, Greenland and Svalbard sites (Eugster et al., 2000; Westermann et al., 2009), while ground heat fluxes from other Siberian sites reported by Kodama et al. (2007) and Boike et al. (1998) fall in the same range. The main reasons for this are most likely similarly cold permafrost temperatures and a similarly large annual temperature amplitude due to the continental climate conditions. 


\section{Conclusions}

In this study, we present measurements of the surface energy balance at a polygonal tundra landscape in northern Siberia for two spring, summer and fall seasons (April-September). Furthermore, the study includes rarely available data on the spatial variablity of the surface energy balance from the point scale to a few hundred meters. In a companion paper (Langer et al., 2010b), a similar data set is presented for the winter season, so that the entire annual cycle of the surface energy balance can be documented.

In the following, we briefly summarize the key findings on the surface energy balance from spring to fall:

- Clouds have a strong impact on the net radiation and thus on the surface energy balance. A significant impact on the soil temperatures has been observed in fall, when a cloud cover has the potential to delay the beginning of freeze back of the tundra soil by at least a week.

- The deviation of net radiation between water bodies and tundra soils is at maximum immediately before and after melting of the ice cover on the pond in spring. Depending on their spatial extent, small water bodies can decrease the summertime surface albedo.

- The timing of the snow melt coincides with the occurrence of negative sensible heat fluxes. This indicates that the advection of warm air masses might be a triggering factor for the snow melt at the study site.

- The partitioning of sensible and latent heat fluxes during the summer months is strongly related to the polygonal surface structures. At the elevated and dry surfaces of the polygonal rims similar fractions of energy are attributed to sensible and latent heat fluxes. At the wet surfaces of the polygonal centers, the turbulent flux is almost completely determined by the latent heat flux.

- The ground heat flux is of similar magnitude as the sensible heat flux, and thus constitutes an important term in the surface energy balance. The high ground heat flux is caused by strong temperature gradients in the shallow active layer and in the frozen soil, which results from both the continental climate and a high soil-water and ice content.

The surface energy balance is the key to a more complete understanding of the coupled permafrost-snow-atmosphere system, that characterizes the vast land areas in the Arctic. Moreover, the realistic representation of the driving factors and processes of the surface energy balance in climate modeling is a prerequisite to develop reliable projections of the future climate in high-latitude regions (Betts et al., 2001, 2003). With its largely quantitative approach and its comprehensive coverage of all components of the surface energy balance, the present study is well suited to support such modeling efforts by providing accessible ground-thruth information on the surface energy balance. While the present work has been conducted for polygonal tundra in Siberia, similar studies at various locations across the climatic and ecological gradients in permafrost areas are highly desirable. An accessible pan-arctic data base on the surface energy balance could significantly contribute to our knowledge on highlatitude ecosystems and on the driving processes, that will shape these areas in the future.

\section{Appendix A}

\section{Definitions and constants}

$Q_{\text {net }}:$ net radiation

$Q_{\mathrm{S} \downarrow}$ : incoming short-wave radiation

$Q_{\mathrm{S} \uparrow}$ : outgoing short-wave radiation

$\Delta Q_{\mathrm{S}}$ : net short-wave radiation

$Q_{\mathrm{L} \downarrow}$ : incoming long-wave radiation

$Q_{\mathrm{L} \uparrow}$ : outgoing long-wave radiation

$\Delta Q_{\mathrm{L}}:$ net long-wave radiation

$Q_{\mathrm{HB}}$ : buoyancy flux

$Q_{\mathrm{H}}$ : sensible heat flux

$Q_{\mathrm{E}}$ : latent heat flux

$Q_{\mathrm{G}}$ : ground or snow heat flux

$Q_{\text {melt }}$ : energy flux through melting of the snow pack

$E_{\text {melt }}$ : latent heat content of the snow pack

$C$ : residual of the energy balance

$u$ : horizontal wind speed

$w$ : vertical wind speed

$u_{*}$ : friction velocity

$z_{0}$ : aerodynamic roughness length

$T_{\text {air }}$ : air temperature

$T_{\text {surf: }}$ surface temperature

$T_{\mathrm{a}}$ : absolute air temperature

$T_{\mathrm{s}}$ : sonic air temperature

$T_{\mathrm{v}}$ : virtual air temperature

$T$ : soil temperature

$q$ : specific humidity

RH: relative humidity

$c_{p}$ : specific heat capacity of air at constant pressure

$\alpha$ : surface albedo

$\epsilon$ : surface emissivity

$\zeta=z / L_{*}:$ stability parameter $\left(z\right.$ : measurement height, $L_{*}$ :

Obukhov length)

$\theta$ : unfrozen volumetric soil water content

$\theta_{\max }:$ maximum volumetric soil water content

$\kappa=0.4$ : von Kármán constant

$\rho_{\text {air }}$ : density of air

$\rho_{\mathrm{w}}=1.0 \mathrm{~g} \mathrm{~cm}^{-3}$ : density of water

$\rho_{\text {ice }}=0.91 \mathrm{~g} \mathrm{~cm}^{-3}$ : density of ice

$\sigma$ : Stefan-Boltzmann constant

$L_{\mathrm{sl}}=0.33 \mathrm{MJ} \mathrm{kg}^{-1}$ : specific latent heat of fusion of water 
$L_{\lg }=2.5 \mathrm{MJ} \mathrm{kg}^{-1}:$ specific latent heat of vaporization of water

$L_{\mathrm{sg}}=2.8 \mathrm{MJ} \mathrm{kg}^{-1}$ : specific latent heat of sublimation of ice

$P_{\text {dry }}$ : porosity of soil

$D_{\mathrm{h}}$ : thermal diffusivity of soil

$K_{\mathrm{h}}$ : thermal conductivity of soil

$C_{\mathrm{h}}$ : volumetric heat capacity of soil

$C_{\mathrm{h}, \mathrm{w}}=4.2 \mathrm{MJ} \mathrm{m}^{-3} \mathrm{~K}^{-1}$ : volumetric heat capacity of water

$C_{\mathrm{h}, \mathrm{i}}=1.9 \mathrm{MJ} \mathrm{m}^{-3} \mathrm{~K}^{-1}$ : volumetric heat capacity of ice

$C_{\mathrm{h}, \mathrm{a}} \approx 0.001 \mathrm{MJ} \mathrm{m}^{-3} \mathrm{~K}^{-1}$ : volumetric heat capacity of air

$C_{\mathrm{h}, \mathrm{s}} \approx 2.3 \mathrm{MJ} \mathrm{m}^{-3} \mathrm{~K}^{-1}$ : volumetric heat capacity of the solid soil matrix

A bulk heat capacity $C_{\mathrm{h}, \mathrm{s}}$ is used for the solid matrix, since typical values of organic and mineral soils do not differ more than $20 \%$ from each other (cf. Sect. 3.3.3)

\section{Appendix B}

\section{The calorimetric method}

The change of the sensible heat content of a soil volume with area $A$ and depth $z$ with uniform temperature and a constant heat capacity is given by

$$
E\left(t_{2}\right)-E\left(t_{1}\right)=A z C_{\mathrm{h}}\left(T\left(t_{2}\right)-T\left(t_{1}\right)\right),
$$

where $T\left(t_{1}\right)$ and $T\left(t_{2}\right)$ are the temperatures at times $t_{1}$ and $t_{2}$. In the case of a temperature dependence of the heat capacity and non-uniform temperature distribution in depth $C_{\mathrm{h}}(T(t, z))$, Eq. (B1) must be rewritten to

$E\left(t_{2}\right)-E\left(t_{1}\right)=A \int_{0}^{z} \int_{T\left(t_{1}, z^{\prime}\right)}^{T\left(t_{2}, z^{\prime}\right)} C_{\mathrm{h}}\left(T^{\prime}\right) d T^{\prime} d z^{\prime}$.

The temperature dependence of $C_{\mathrm{h}}$ is caused by the phase change of water and is calculated as

$$
\begin{aligned}
C_{\mathrm{h}}(T) & =\theta(T) C_{\mathrm{h}, \mathrm{w}}+\left(\theta_{\max }-\theta(T)\right) C_{\mathrm{h}, \mathrm{i}} \\
& +\left(1-P_{\mathrm{dry}}\right) C_{\mathrm{h}, \mathrm{s}},
\end{aligned}
$$

where $P_{\text {dry }}$ is the porosity of the soil, $\theta_{\max }$ is the maximum volumetric unfrozen water content, and $\theta(T)$ is the temperature-dependent volumetric liquid water content, which is referred to as "freeze characteristic". The volumetric fraction of the solid matrix and thus the porosity is determined from soil samples and the volumetric water and ice content is obtained from in situ TDR-measurements (see Boike et al., 2003, for details). To account for the release or consumption of energy through freezing and thawing, Eq. (B2) is extended to

$$
\begin{aligned}
E\left(t_{2}\right)-E\left(t_{1}\right) & =A \int_{0}^{z} \rho_{\mathrm{w}} L_{\mathrm{sl}}\left[\theta\left(T\left(t_{2}, z^{\prime}\right)\right)-\theta\left(T\left(t_{1}, z^{\prime}\right)\right)\right] d z^{\prime} \\
& +A \int_{0}^{z} \int_{T\left(t_{1}, z^{\prime}\right)}^{T\left(t_{2}, z^{\prime}\right)} C_{\mathrm{h}}\left(T^{\prime}\right) d T^{\prime} d z^{\prime}
\end{aligned}
$$

This method of ground heat flux determination requires knowledge about the soil-specific freeze characteristics or direct measurements of the volumetric soil water content. The used soil-temperature measurements must extend to a depth of constant temperatures during the considered measurement period. If such a deep temperature profile is not available, the heat flux below the measurement depth can be obtained by solving the heat transfer equation at the lower boundary (Eq. C3, see below).

\section{Appendix C}

\section{The conductive method}

The conductive method makes use of the heat transfer equation to determine the ground heat flux. Firstly, the thermal conductivity of the soil or snow must be evaluated. This procedure requires a time series of soil temperatures, measured in a profile at three depths, $T_{\mathrm{m}}\left(z_{1}, t\right), T_{\mathrm{m}}\left(z_{2}, t\right)$ and $T_{\mathrm{m}}\left(z_{3}, t\right)$ with $z_{1}<z_{2}<z_{3}$. The one-dimensional heat transfer equation is written as

$C_{\mathrm{h}}(t, z) \frac{\partial T(t, z)}{\partial t}=\frac{\partial}{\partial z} K_{\mathrm{h}}(t, z) \frac{\partial T(t, z)}{\partial z}$,

where $T(t, z)$ denotes the soil or snow temperature at time $t$ and depth $z$. Assuming constant heat capacities and thermal conductivities $K_{\mathrm{h}}(t, z)$ in space and time, the onedimensional heat transfer equation is simplified to

$\frac{\partial T(z, t)}{\partial t}=D_{\mathrm{h}} \frac{\partial^{2} T(z, t)}{\partial z^{2}}$,

where $D_{\mathrm{h}}=K_{\mathrm{h}} / C_{\mathrm{h}}$ denotes the thermal diffusivity. The solution of (Eq. C2) is obtained by the partial differential equation solver incorporated in MATLAB. The required boundary conditions are given by the outer sensors of the temperature profile, $T_{\mathrm{m}}\left(z_{1}, t\right)$ and $T_{\mathrm{m}}\left(z_{3}, t\right)$. The initial conditions are inferred from linear interpolation between all the three sensors at $t=0$, which is not critical to the solution, since it becomes independent of the initial temperature state after a few time steps in the shallow soil layer. The numerical solver delivers the temperature distribution of the considered spatial domain, including $T\left(t, z_{2}\right)$, so that the thermal diffusivity $D_{\mathrm{h}}$ can be evaluated by minimizing the least mean square error to the measured temperatures at depth $z_{2}, T_{\mathrm{m}}\left(t, z_{2}\right)$. We use time series of several days for the determination of the thermal diffusivity of different surface substrates (see Table 1). Note that this procedure assumes homogeneous substrate composition in the considered soil or snow layer, which may not be the case in nature. The heat flux through the upper boundary can be evaluated by

$Q_{\mathrm{G}}(t)=\left.D_{\mathrm{h}} C_{\mathrm{h}} \frac{\partial T(z, t)}{\partial z}\right|_{z=z_{1}}$.

The conductive methods has been applied by Westermann et al. (2009); similar concepts are explored by Nicolsky et al. (2009). 


\section{Appendix D}

\section{Modeling of latent heat fluxes}

This model approach is used when eddy covariance measurements of the latent heat flux are not available. The model is based on eddy covariance measurements of wind speed and sonic temperature and uses ancillary measurements of relative humidity and surface temperature. The model is based on commonly used parameterizations of the atmospheric transport mechanisms (Foken, 2006), which we describe next. According to Monin-Obukhov similarity theory, the latent heat flux can be related to the difference between specific humidity at measurement height $\bar{q}\left(z_{\mathrm{m}}\right)$ and roughness length $\bar{q}\left(z_{0}\right)$ by

$\overline{q^{\prime} w^{\prime}}=\left(\bar{q}\left(z_{\mathrm{m}}\right)-\bar{q}\left(z_{0}\right)\right) \kappa u_{*}\left[\ln \frac{z_{\mathrm{m}}}{z_{0}}-\Psi_{W}\left(\frac{z_{\mathrm{m}}}{L_{*}}, \frac{z_{0}}{L_{*}}\right)\right]^{-1}$

with

$\Psi_{W}\left(\frac{z_{\mathrm{m}}}{L_{*}}, \frac{z_{0}}{L_{*}}\right)=\int_{z_{0}}^{z_{\mathrm{m}}} \frac{1-\varphi_{W}\left(z^{\prime} / L_{*}\right)}{z^{\prime}} d z^{\prime}$,

where $\kappa$ denotes the von Kármán constant constant (0.4), $u_{*}$ the friction velocity, and $\varphi\left(z / L_{*}\right)$ is a universal function (see below). The quotient $z / L_{*}$ denotes the stability parameter $\zeta$, where $L_{*}$ is the Obukhov length defined in Eq. (D6). Using Eq. (D1) and rewriting the turbulent transport terms as atmospheric resistance $r_{\mathrm{a}}$, the latent heat flux $Q_{\mathrm{E}}$ can be evaluated by

$Q_{\mathrm{E}}=-\frac{\rho_{\mathrm{air}} L_{\mathrm{lg}}}{r_{\mathrm{a}}}\left(\bar{q}\left(z_{\mathrm{m}}\right)-\bar{q}\left(z_{0}\right)\right)$,

with

$r_{\mathrm{a}}:=\left(\kappa u_{*}\right)^{-1}\left[\ln \frac{z_{\mathrm{m}}}{z_{0}}-\Psi_{W}\left(\frac{z_{\mathrm{m}}}{L_{*}}, \frac{z_{0}}{L_{*}}\right)\right]$,

where $\rho_{\text {air }}$ is the density of air, $L_{\lg }$ the latent heat of vaporization of water (Garratt, 1994). For calculation over the snow surface, the term for vaporization, $L_{\mathrm{lg}}$, must be substituted by the latent heat of sublimation $L_{\mathrm{sg}}$. The specific humidity at a saturated surfaces $q\left(z_{0}\right)$ can be inferred from to the surface temperature $T_{\text {surf }}$ by using the Magnus formula, giving the water vapor pressure over a water surface or an ice surface, respectively. During the summer months the surface is not entirely saturated and a surface resistance to evapotranspiration $r_{\mathrm{s}}$ must be added to $r_{\mathrm{a}}$ in Eq. (D3) to account for the reduced availability, if the Magnus formula is applied. We use measured time series of the latent heat flux to fit the surface resistance of summer and fall. We assume the surface resistance to be constant in time. The roughness length $z_{0}$ can be inferred from measurements of $u_{*}^{2}$ under neutral atmospheric conditions (Foken, 2006). Note that we assume the aerodynamic roughness length to be the roughness length of water vapor. The fitting procedure yields a surface resistance of about $50 \mathrm{~s} \mathrm{~m}^{-1}$, with a roughness length determined to be $10^{-3} \mathrm{~m}$ during the summer period. When the ground is snow-covered, the surface resistance is set to zero, while the roughness is determined to $5 \times 10^{-4} \mathrm{~m}$. The universal function $\Psi_{W}$ is chosen according to Høgstrøm (1988) as

$\varphi_{W}(\zeta)= \begin{cases}0.95(1-11.6 \zeta)^{-1 / 4} & \text { for } \zeta \leq 0 \\ 0.95+7.8 \zeta & \text { for } \zeta>0\end{cases}$

The Obukhov length $L_{*}$, which is required for the stability parameter $\zeta$, is directly obtained from eddy covariance measurements using

$L_{*}=-\frac{u_{*}^{3} \bar{T}_{\mathrm{v}}}{\kappa g\left(\overline{T_{\mathrm{v}}^{\prime} w^{\prime}}\right)}$,

where $g$ is the gravitational acceleration and $T_{\mathrm{v}}$ the virtual temperature. Note that the virtual temperature $T_{\mathrm{v}}$ is substituted by the sonic temperature $T_{\mathrm{S}}$ (Foken, 2006).

Acknowledgements. We are thankful to the Department of MicroMeteorology of the University of Bayreuth, headed by Thomas Foken, for providing the eddy covariance post-processing software. We are also thankful to Claudia Fiencke and Tina Sanders of the Institute of Soil Science of the University of Hamburg for the soil component analyses. We gratefully acknowledge financial support by the Helmholtz Association through a grant (VH-NG 203) awarded to Julia Boike.

Edited by: D. Riseborough

\section{References}

Are, F. and Reimnitz, E.: An overview of the Lena River Delta setting: geology, tectonics, geomorphology, and hydrology, J. Coastal Res., 16, 1083-1093, 2000.

Baker, J. and Baker, D.: Long-term ground heat flux and heat storage at a mid-latitude site, Climatic Change, 54, 295-303, 2002.

Betts, A., Viterbo, P., Beljaars, A., and Van den Hurk, B.: Impact of BOREAS on the ECMWF forecast model, J. Geophys. Res.Atmos., 106, 148-227, 2001.

Betts, A., Ball, J., and Viterbo, P.: Evaluation of the ERA-40 surface water budget and surface temperature for the Mackenzie River basin, J. Hydrometeorol., 4, 1194-1211, 2003.

Boike, J., Roth, K., and Overduin, P.: Thermal and hydrologic dynamics of the active layer at a continuous permafrost site (Taymyr Peninsula, Siberia), Water Resour. Res., 34, 355-363, 1998.

Boike, J., Roth, K., and Ippisch, O.: Seasonal snow cover on frozen ground: Energy balance calculations of a permafrost site near Ny-Alesund, Spitsbergen, J. Geophys. Res.-Atmos., 108, 81638173, 2003.

Boike, J., Wille, C., and Abnizova, A.: Climatology and summer energy and water balance of polygonal tundra in the Lena River Delta, Siberia, J. Geophys. Res.-Biogeo., 113, G03025, doi:10.1029/2007JG000540, 2008.

Boone, A., Decharme, B., Guichard, F., de Rosnay, P., Balsamo, G., Beljaars, A., Chopin, F., Orgeval, T., Polcher, J., Delire, C., Ducharne, A., Gascoin, S., Grippa, M., Jarlan, L., Kergoat, L., Mougin, E., Gusev, Y., Nasonova, O., Harris, P., Taylor, C., 
Norgaard, A., Sandholt, I., Ottlé, C., Poccard-Leclercq, I., SauxPicart, S., and Xue, Y.: The AMMA Land Surface Model Intercomparison Project (ALMIP), B. Am. Meteorol. Soc., 90, 18651880, 2009.

Brotzge, J. and Duchon, C.: A field comparison among a domeless net radiometer, two four-component net radiometers, and a domed net radiometer, J. Atmos. Ocean. Tech., 17(12), 15691582, 2000.

Brown, J., Ferrians Jr., O., Heginbottom, J., and Melnikov, E.: Circum-Arctic map of permafrost and ground-ice conditions, US Geological Survey Circum-Pacific Map, 1997.

Bugbee, B., Droter, M., Monje, O., and Tanner, B.: Evaluation and modification of commercial infra-red transducers for leaf temperature measurement, Adv. Space Res., 22, 1425-1434, 1998.

Callaghan, T. V., Björn, L. O., Chernov, Y., Chapin, T., Christensen, T. R., Huntley, B., Ims, R. A., Johansson, M., Jolly, D., Jonasson, S., Matveyeva, N., Panikov, N., Oechel, W., Shaver, G., Schaphoff, S., and Sitch, S.: Effects of changes in climate on landscape and regional processes, and feedbacks to the climate system, AMBIO, 33, 459-468, 2004.

Chapin, F., Eugster, W., McFadden, J., Lynch, A., and Walker, D.: Summer differences among arctic ecosystems in regional climate forcing, J. Climate, 13, 2002-2010, 2000.

Christensen, T. and Cox, P.: Response of methane emission from Arctic tundra to climatic change: Results from a model simulation, Tellus B, 47, 301-309, 1995.

Christensen, T., Ekberg, A., Ström, L., Mastepanov, M., Panikov, N., Öquist, M., Svensson, B., Nykänen, H., Martikainen, P., and Oskarsson, H.: Factors controlling large scale variations in methane emissions from wetlands, Geophys. Res. Lett, 30, 1414, doi:10.1029/2002GL016848, 2003.

Comiso, J.: Arctic warming signals from satellite observations, Weather, 61(3), 70-76, 2006.

Cox, P., Betts, R., Bunton, C., Essery, R., Rowntree, P., and Smith, J.: The impact of new land surface physics on the GCM simulation of climate and climate sensitivity, Clim. Dynam., 15, 183203, 1999

Curry, J., Rossow, W., Randall, D., and Schramm, J.: Overview of Arctic cloud and radiation characteristics, J. Climate, 9, 17311764, 1996.

Davidson, E. and Janssens, I.: Temperature sensitivity of soil carbon decomposition and feedbacks to climate change, Nature, 440, 165-173, 2006.

Eugster, W., Rouse, W., Pielke Sr., R., McFadden, J., Baldocchi, D., Kittel, T., Chapin, F., Liston, G., Vidale, P., Vaganov, E., and Chambers, S.: Land-atmosphere energy exchange in Arctic tundra and boreal forest: available data and feedbacks to climate, Glob. Change Biol., 6, 84-115, 2000.

Foken, T.: Angewandte Meteorologie: Mikrometeorologische Methoden, Springer Verlag, Berlin Heidelberg, 326 pp., 2006.

Foken, T.: The energy balance closure problem - An overview, Ecol. Appl., 18, 1351-1367, 2008.

Foken, T. and Wichura, B.: Tools for quality assessment of surfacebased flux measurements, Agr. Forest Meteorol., 78, 83-105, 1996.

Foken, T., Göckede, M., Mauder, M., Mahrt, L., Amiro, B., and Munger, J.: Post-field data quality control, in: Handbook of Micrometeorology: A Guide for Surface Flux Measurement and Analysis, Atmospheric and Oceanographic Sciences Library, edited by: Lee, X., Massman, W., and Law, B., Springer Netherlands, 29, 181-208, doi:10.1007/1-4020-2265-4_9, 2005.

Garratt, J.: The atmospheric boundary layer, Cambridge University Press, Cambridge, UK, 334 pp., 1994.

Goodrich, L.: The influence of snow cover on the ground thermal regime, Can. Geotech. J., 19, 421-432, 1982.

Grigoriev, N.: The temperature of permafrost in the Lena delta basin - deposit conditions and properties of the permafrost in Yakutia, chap. 2, 97-101, Yakutsk, 1960 (in Russian).

Hansen, J., Ruedy, R., Sato, M., Imhoff, M., Lawrence, W., Easterling, D., Peterson, T., and Karl, T.: A closer look at United States and global surface temperature change, J. Geophys. Res.-Atmos., 106, 23947-23963, 2001.

Harazono, Y., Yoshimoto, M., Mano, M., Vourlitis, G., and Oechel, W.: Characteristics of energy and water budgets over wet sedge and tussock tundra ecosystems at North Slope in Alaska, Hydrol. Process., 12, 2163-2183, 1998.

Harding, R. and Lloyd, C.: Fluxes of water and energy from three high latitude tundra sites in Svalbard, Nord. Hydrol., 29, 267284, 1998.

Hinzman, L., Bettez, N., Bolton, W., Chapin, F., Dyurgerov, M., Fastie, C., Griffith, B., Hollister, R., Hope, A., Huntington, H., Jensen, A., Jia, G., Jorgenson, T., Kane, D., Klein, D., Kofinas, G., Lynch, A., Lloyd, A., McGuire, A., Nelson, F., Oechel, W., Osterkamp, T., Racine, C., Romanovsky, V., Stone, R., Stow, D., Sturm, M., Tweedie, C., Vourlitis, G., Walker, M., Walker, D., Webber, P., Welker, J., Winker, K., and Yoshikawa, K.: Evidence and implications of recent climate change in northern Alaska and other arctic regions, Climatic Change, 72, 251-298, 2005.

Hobbie, S., Schimel, J., Trumbore, S., and Randerson, J.: Controls over carbon storage and turnover in high-latitude soils, Glob. Change Biol., 6, 196-210, 2000.

Høgstrøm, U.: Non-dimensional wind and temperature profiles in the atmospheric surface layer: A re-evaluation, Bound.-Lay. Meteorol., 42, 55-78, 1988.

Iijima, Y., Masuda, K., and Ohata, T.: Snow disappearance in Eastern Siberia and its relationship to atmospheric influences, Int. J. Climatol., 27, 169-178, 2007.

Inagaki, A., Letzel, M., Raasch, S., and Kanda, M.: Impact of surface heterogeneity on energy balance: A study using LES, J. Meteorol. Soc. Jpn., 84, 187-198, 1996.

Intrieri, J., Shupe, M., Uttal, T., and McCarty, B.: An annual cycle of Arctic cloud characteristics observed by radar and lidar at SHEBA, J. Geophys. Res.-Oceans, 107, 8030, doi:10.1029/2000JC000423, 2002.

Kodama, Y., Sato, N., Yabuki, H., Ishii, Y., Nomura, M., and Ohata, T.: Wind direction dependency of water and energy fluxes and synoptic conditions over a tundra near Tiksi, Siberia, Hydrol. Process., 21, 2028-2037, 2007.

Kohsiek, W., Liebethal, C., Foken, T., Vogt, R., Oncley, S., Bernhofer, C., and Debruin, H.: The Energy Balance Experiment EBEX-2000. Part III: Behaviour and quality of the radiation measurements, Bound.-Lay. Meteorol., 123, 55-75, 2007.

Krinner, G.: Impact of lakes and wetlands on boreal climate, J. Geophys. Res.-Atmos., 108, 4520, doi:10.1029/2002JD002597, 2003.

Krinner, G. and Boike, J.: A study of the large-scale climatic effects of a possible disappearance of high-latitude inland water surfaces during the 21st century, Boreal Environ. Res., 15, 203-217, 
2010.

Kutzbach, L., Wagner, D., and Pfeiffer, E.: Effect of microrelief and vegetation on methane emission from wet polygonal tundra, Lena Delta, Northern Siberia, Biogeochemistry, 69, 341-362, 2004.

Kutzbach, L., Wille, C., and Pfeiffer, E.-M.: The exchange of carbon dioxide between wet arctic tundra and the atmosphere at the Lena River Delta, Northern Siberia, Biogeosciences, 4, 869-890, doi:10.5194/bg-4-869-2007, 2007.

Langer, M., Westermann, S., and Boike, J.: Spatial and temporal variations of summer surface temperatures of wet polygonal tundra in Siberia - implications for MODIS LST based permafrost monitoring, Remote Sens. Environ., 114, 2059-2069, 2010a.

Langer, M., Westermann, S., Muster, S., Piel, K., and Boike, J.: Permafrost and surface energy balance of a polygonal tundra site in Northern Siberia - Part 2: Winter, The Cryosphere Discuss., 4, 1391-1431, doi:10.5194/tcd-4-1391-2010, 2010 b.

Lawrence, D. and Slater, A.: A projection of severe near-surface permafrost degradation during the 21 st century, Geophys. Res. Lett, 32, L24401, doi:10.1029/2005GL025080, 2005.

Lawrence, D., Slater, A., Romanovsky, V., and Nicolsky, D.: Sensitivity of a model projection of near-surface permafrost degradation to soil column depth and representation of soil organic matter, J. Geophys. Res, 113, F02011, doi:10.1029/2007JF000883, 2008.

Ling, F. and Zhang, T.: Modeled impacts of changes in tundra snow thickness on ground thermal regime and heat flow to the atmosphere in Northernmost Alaska, Global Planet. Change, 57, 235246, 2007.

Liu, H. and Foken, T.: A modified Bowen ratio method to determine sensible and latent heat fluxes, Meteorol. Z., 10, 71-80, 2001.

Lloyd, C., Harding, R., Friborg, T., and Aurela, M.: Surface fluxes of heat and water vapour from sites in the European Arctic, Theor. Appl. Climatol., 70, 19-33, 2001.

Lynch, A., Chapin, F., Hinzman, L., Wu, W., Lilly, E., Vourlitis, G., and Kim, E.: Surface energy balance on the arctic tundra: Measurements and models, J. Climate, 12, 2585-2606, 1999.

Mastepanov, M., Sigsgaard, C., Dlugokencky, E., Houweling, S., Ström, L., Tamstorf, M., and Christensen, T.: Large tundra methane burst during onset of freezing, Nature, 456, 628-630, 2008

Mauder, M. and Foken, T.: Documentation and instruction manual of the eddy covariance software package TK2, Univ. of Bayreuth, Dept. of Mikrometeorology, 2004.

Mauder, M., Liebethal, C., Göckede, M., Leps, J., Beyrich, F., and Foken, T.: Processing and quality control of flux data during LITFASS-2003, Bound.-Lay. Meteorol., 121, 67-88, 2006.

Mauder, M., Foken, T., Clement, R., Elbers, J. A., Eugster, W., Grünwald, T., Heusinkveld, B., and Kolle, O.: Quality control of CarboEurope flux data - Part 2: Inter-comparison of eddy-covariance software, Biogeosciences, 5, 451-462, doi:10.5194/bg-5-451-2008, 2008.

McGuire, A., Chapin, F., Walsh, J., and Wirth, C.: Integrated Regional Changes in Arctic Climate Feedbacks: Implications for the Global Climate System, Annu. Rev. Env. Resour., 31, 61-91, 2006.

Mendez, J., Hinzman, L., and Kane, D.: Evapotranspiration from a wetland complex on the Arctic coastal plain of Alaska, Nord. Hydrol., 29, 303-330, 1998.
Moore, C.: Frequency response corrections for eddy correlation systems, Bound.-Lay. Meteorol., 37, 17-35, 1986.

Nicolsky, D., Romanovsky, V., Alexeev, V., and Lawrence, D.: Improved modeling of permafrost dynamics in a GCM land-surface scheme, Geophys. Res. Lett., 34, L08501, doi:10.1029/2007GL029525, 2007.

Nicolsky, D., Romanovsky, V., and Panteleev, G.: Estimation of soil thermal properties using in-situ temperature measurements in the active layer and permafrost, Cold Reg. Sci. Technol., 55, 120-129, 2009.

Ohmura, A.: Climate and energy balance on the arctic tundra, Int. J. Climatol., 2, 65-84, 1982.

Ohmura, A.: Comparative energy balance study for arctic tundra, sea surface glaciers and boreal forests, Geojournal, 8, 221-228, 1984.

Oke, T.: Boundary layer climates, Methuen, London, 464 pp., 1987.

Overland, J., Wang, M., and Salo, S.: The recent Arctic warm period, Tellus A, 60, 589-597, 2008.

Overpeck, J., Hughen, K., Hardy, D., Bradley, R., Case, R., Douglas, M., Finney, B., Gajewski, K., Jacoby, G., Jennings, A., Lamoureux, S., Lasca, A., MacDonald, G., Moore, J., Retelle, M., Smith, S., Wolfe, A., and Zielinski, G.: Arctic environmental change of the last four centuries, Science, 278, 1251-1256, doi:10.1126/science.278.5341.1251, 1997.

Peters-Lidard, C., Blackburn, E., Liang, X., and Wood, E.: The effect of soil thermal conductivity parameterization on surface energy fluxes and temperatures, J. Atmos. Sci., 55, 1209-1224, 1998.

Pitman, A.: The evolution of, and revolution in, land surface schemes designed for climate models, Int. J. Climatol., 23, 479510, 2003.

Romanovsky, V. and Osterkamp, T.: Thawing of the active layer on the coastal plain of the Alaskan Arctic, Permafrost Periglac., 8, 1-22, 1997.

Rouse, W., Oswald, C., Binyamin, J., Spence, C., Schertzer, W., Blanken, P., Bussières, N., and Duguay, C.: The role of northern lakes in a regional energy balance, J. Hydrometeorol., 6, 291305, 2005.

Sachs, T., Wille, C., Boike, J., and Kutzbach, L.: Environmental controls on ecosystem-scale $\mathrm{CH} 4$ emission from polygonal tundra in the Lena River Delta, Siberia, J. Geophys. Res.-Biogeo., 113, G00A03, doi:10.1029/2007JG000505, 2008.

Schmid, H.: Source areas for scalars and scalar fluxes, Bound.-Lay. Meteorol., 67, 293-318, 1994.

Schotanus, P., Nieuwstadt, F., and Bruin, H.: Temperature measurement with a sonic anemometer and its application to heat and moisture fluxes, Bound.-Lay. Meteorol., 26, 81-93, 1983.

Serreze, M., Walsh, J., Chapin, F., Osterkamp, T., Dyurgerov, M., Romanovsky, V., Oechel, W., Morison, J., Zhang, T., and Barry, R.: Observational evidence of recent change in the northern highlatitude environment, Climatic Change, 46, 159-207, 2000.

Shupe, M. and Intrieri, J.: Cloud radiative forcing of the Arctic surface: The influence of cloud properties, surface albedo, and solar zenith angle, J. Climate, 17, 616-628, doi:10.1175/15200442(2004)017<0616:CRFOTA > 2.0.CO;2, 2004.

Soegaard, H., Hasholt, B., Friborg, T., and Nordstroem, C.: Surface energy-and water balance in a high-arcticenvironment in $\mathrm{NE}$ Greenland, Theor. Appl. Climatol., 70, 35-51, 2001.

Stendel, M. and Christensen, J.: Impact of global warming on 
permafrost conditions in a coupled GCM, Geophys. Res. Lett., 29, 1632, doi:10.1029/2001GL014345, 2002.

Sturm, M., Holmgren, J., König, M., and Morris, K.: The thermal conductivity of seasonal snow, J. Glaciol., 43, 26-41, 1997.

USGS: The Lena River Delta, US Geological Survey: Digital Image, http://eros.usgs.gov/imagegallery/collection.php?type= earth_as_art, 2000.

van den Hurk, B., Viterbo, P., Beljaars, A., and Betts, A.: Offline validation of the ERA40 surface scheme, European Centre for Medium-Range Weather Forecasts, 2000.

Viterbo, P., Beljaars, A., Mahfouf, J., and Teixeira, J.: The representation of soil moisture freezing and its impact on the stable boundary layer, Q. J. Roy. Meteor. Soc., 125, 2401-2426, 1999.

Vourlitis, G. and Oechel, W.: Eddy covariance measurements of CO_2 and energy fluxes of an Alaskan tussock tundra ecosystem, Ecology, 80, 686-701, 1999.

Westermann, S., Lüers, J., Langer, M., Piel, K., and Boike, J.: The annual surface energy budget of a high-arctic permafrost site on Svalbard, Norway, The Cryosphere, 3, 245-263, doi:10.5194/tc3-245-2009, 2009.
Wilczak, J., Oncley, S., and Stage, S.: Sonic anemometer tilt correction algorithms, Bound.-Lay. Meteorol., 99, 127-150, 2001.

Wilson, K., Goldstein, A., Falge, E., Aubinet, M., Baldocchi, D., Berbigier, P., Bernhofer, C., Ceulemans, R., Dolman, H., Field, C., Grelle, A., Ibrom, A., Law, B. E., Kowalski, A., Meyers, T., Moncrieff, J., Monson, R., Oechel, W., Tenhunen, J., Valentini, R., and Verma, S.: Energy balance closure at FLUXNET sites, Agr. Forest Meteorol., 113, 223-243, 2002.

Zhang, T.: Influence of the seasonal snow cover on the ground thermal regime: An overview, Rev. Geophys., 43, RG4002, doi:10.1029/2004RG000157, 2005.

Zhang, X., Walsh, J., Zhang, J., Bhatt, U., and Ikeda, M.: Climatology and interannual variability of Arctic cyclone activity: 1948-2002, J. Climate, 17, 2300-2317, doi:10.1175/15200442(2004)017<2300:CAIVOA > 2.0.CO;2, 2004.

Zimov, S., Schuur, E., and Chapin III, F.: Permafrost and the global carbon budget, Science, 312, 1612-1613, 2006. 